\title{
Emerging Energy-Efficient Technologies in Buildings: Technology Characterizations for Energy Modeling
}

May 2004

Prepared by

Stanton W. Hadley

J. Michael MacDonald

Moonis Ally

John Tomlinson

Marcus Simpson

William Miller 


\title{
DOCUMENT AVAILABILITY
}

Reports produced after January 1, 1996, are generally available free via the U.S. Department of Energy (DOE) Information Bridge:

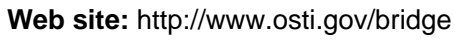

Reports produced before January 1, 1996, may be purchased by members of the public from the following source:

\author{
National Technical Information Service \\ 5285 Port Royal Road \\ Springfield, VA 22161 \\ Telephone: 703-605-6000 (1-800-553-6847) \\ TDD: $703-487-4639$ \\ Fax: 703-605-6900 \\ E-mail: info@ntis.fedworld.gov \\ Web site: http://www.ntis.gov/support/ordernowabout.htm
}

Reports are available to DOE employees, DOE contractors, Energy Technology Data Exchange (ETDE) representatives, and International Nuclear Information System (INIS) representatives from the following source:

Office of Scientific and Technical Information

P.O. Box 62

Oak Ridge, TN 37831

Telephone: $865-576-8401$

Fax: 865-576-5728

E-mail: reports@adonis.osti.gov

Web site: http://www.osti.gov/contact.html

\begin{abstract}
This report was prepared as an account of work sponsored by an agency of the United States Government. Neither the United States government nor any agency thereof, nor any of their employees, makes any warranty, express or implied, or assumes any legal liability or responsibility for the accuracy, completeness, or usefulness of any information, apparatus, product, or process disclosed, or represents that its use would not infringe privately owned rights. Reference herein to any specific commercial product, process, or service by trade name, trademark, manufacturer, or otherwise, does not necessarily constitute or imply its endorsement, recommendation, or favoring by the United States Government or any agency thereof. The views and opinions of authors expressed herein do not necessarily state or reflect those of the United States Government or any agency thereof.
\end{abstract}




\title{
Emerging Energy-Efficient Technologies in Buildings: Technology Characterizations for Energy Modeling
}

\author{
Prepared for the \\ National Commission on Energy Policy \\ Stanton W. Hadley \\ J. Michael MacDonald \\ Moonis Ally \\ John Tomlinson \\ Marcus Simpson \\ William Miller
}

May 2004

OAK RIDGE NATIONAL LABORATORY

Oak Ridge, Tennessee 37831

managed by

UT-BATTELLE, LLC

for the

U.S. DEPARTMENT OF ENERGY

under contract No. DE-AC05-00OR22725 



\section{Abstract}

The energy use in America's commercial and residential building sectors is large and growing. Over 38 quadrillion Btus (Quads) of primary energy were consumed in 2002, representing 39\% of total U.S. energy consumption. While the energy use in buildings is expected to grow to 52 Quads by 2025, a large number of energy-related technologies exist that could curtail this increase. In recent years, improvements in such items as high efficiency refrigerators, compact fluorescent lights, high-SEER air conditioners, and improved building shells have all contributed to reducing energy use. Hundreds of other technology improvements have and will continue to improve the energy use in buildings. While many technologies are well understood and are gradually penetrating the market, more advanced technologies will be introduced in the future. The pace and extent of these advances can be improved through state and federal R\&D.

This report focuses on the long-term potential for energy-efficiency improvement in buildings. Five promising technologies have been selected for description to give an idea of the wide range of possibilities. They address the major areas of energy use in buildings: space conditioning (33\% of building use), water heating (9\%), and lighting (16\%). Besides describing energy-using technologies (solid-state lighting and geothermal heat pumps), the report also discusses energysaving building shell improvements (smart roofs) and the integration of multiple energy service technologies (CHP packaged systems and triple function heat pumps) to create synergistic savings. Finally, information technologies that can improve the efficiency of building operations are discussed.

The report demonstrates that the United States is not running out of technologies to improve energy efficiency and economic and environmental performance, and will not run out in the future. The five technology areas alone can potentially result in total primary energy savings of between 2 and 4.2 Quads by 2025 , or $3.8 \%$ to $8.1 \%$ of the total commercial and residential energy use by 2025 (52 Quads). Many other technologies will contribute to additional potential for energy-efficiency improvement, while the technical potential of these five technologies on the long term is even larger. 


\section{CONTENTS}

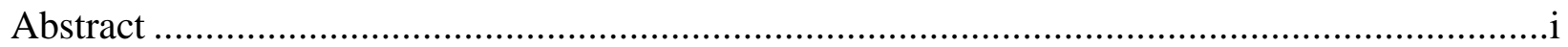

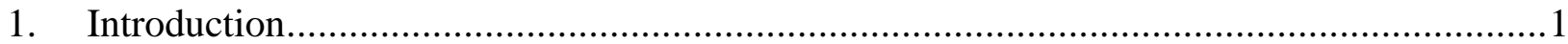

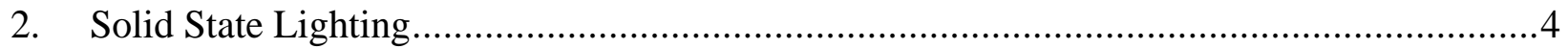

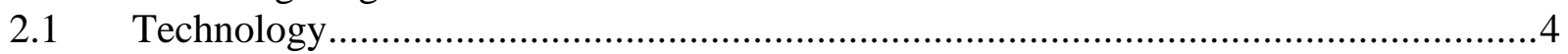

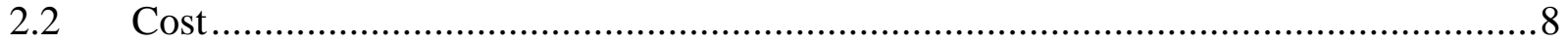

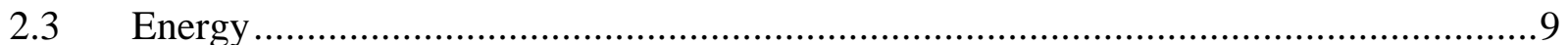

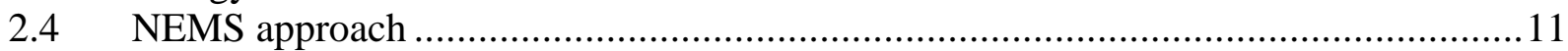

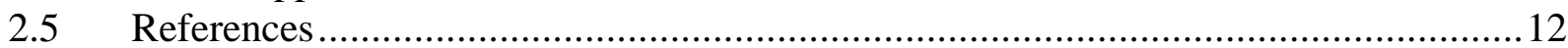

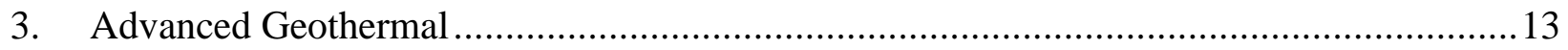

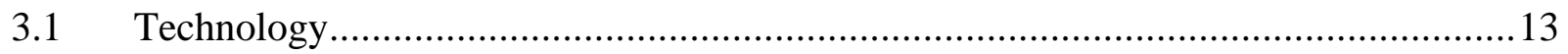

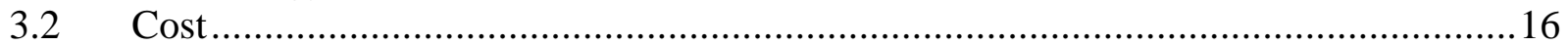

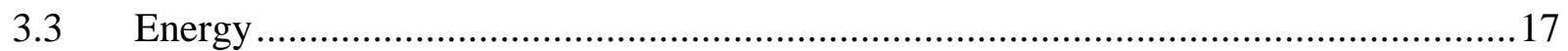

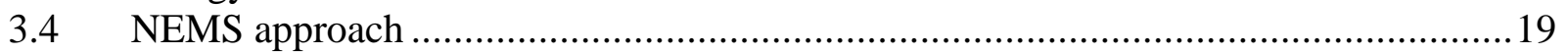

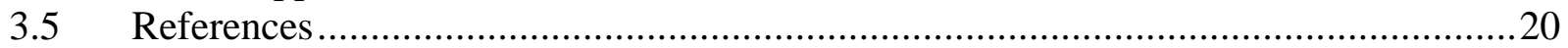

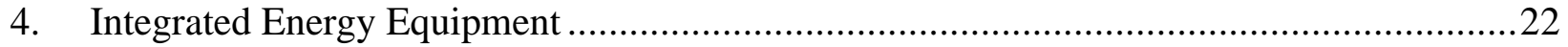

$4.1 \quad$ Technology

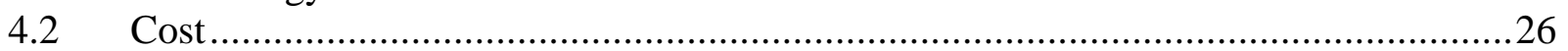

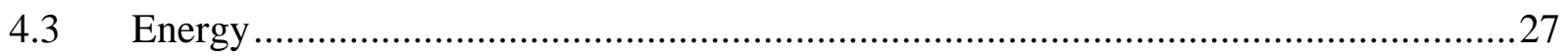

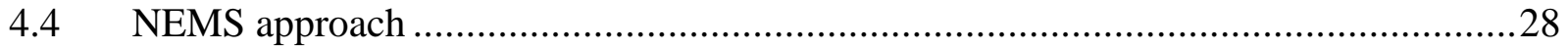

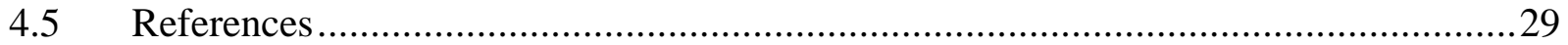

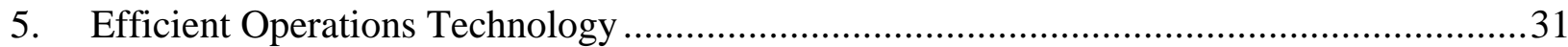

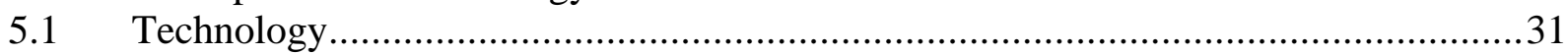

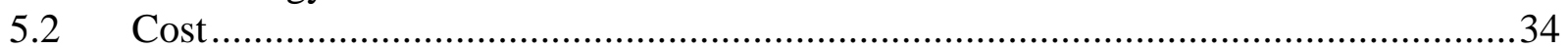

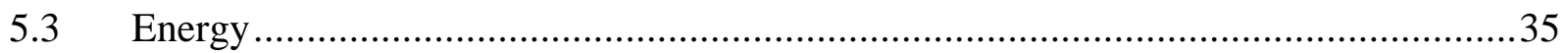

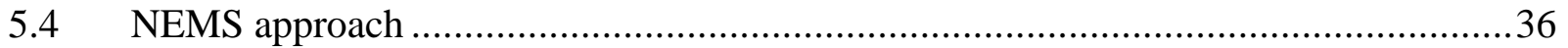

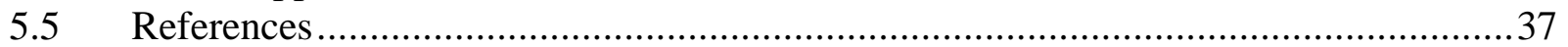

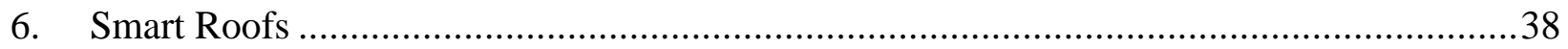

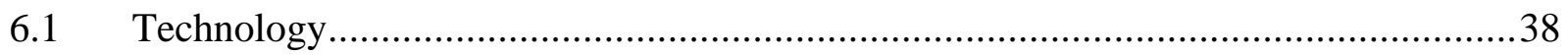

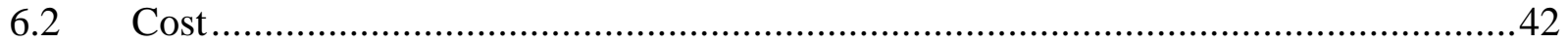

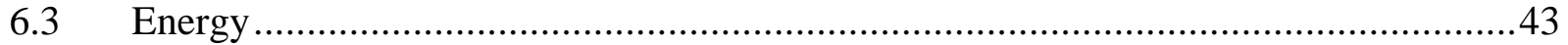

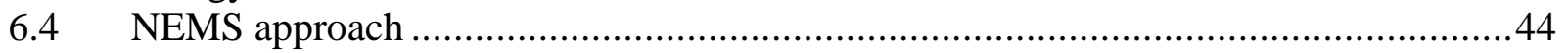

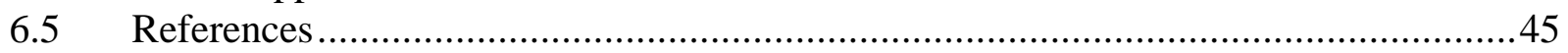

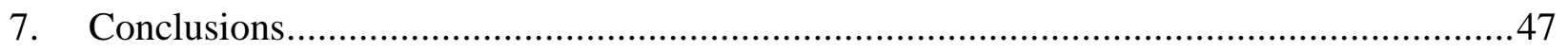




\section{Introduction ${ }^{1}$}

There are a large number of technologies that have the potential to improve energy efficiency in U.S. buildings. In recent years high efficiency refrigerators, compact fluorescent lights, highSEER air conditioners, and improved building shells have all contributed to reducing energy use. Various reports such as the Clean Energy Futures study (Interlaboratory Working Group 2000) and Emerging Energy-Saving Technologies and Practices for the Building Sector (Nadel et al. 1998) have identified many other technology improvements. This paper describes just five of the many technologies that may be deployed to give an idea of the potential available.

The Department of Energy's (DOE's) Energy Information Administration (EIA) annually provides forecasts of energy use over the next twenty to twenty-five years, with their most recent being the Annual Energy Outlook 2004 (AEO2004) (EIA 2003). They use their National Energy Modeling System (NEMS) to calculate the amounts of energy supplied and demanded by different sectors. Figure 1 and Figure 2 show the amount of total primary energy required for various end-uses in the residential and commercial (buildings) sectors.

Figure 1. AEO2004 Reference case residential primary energy use (EIA 2003)

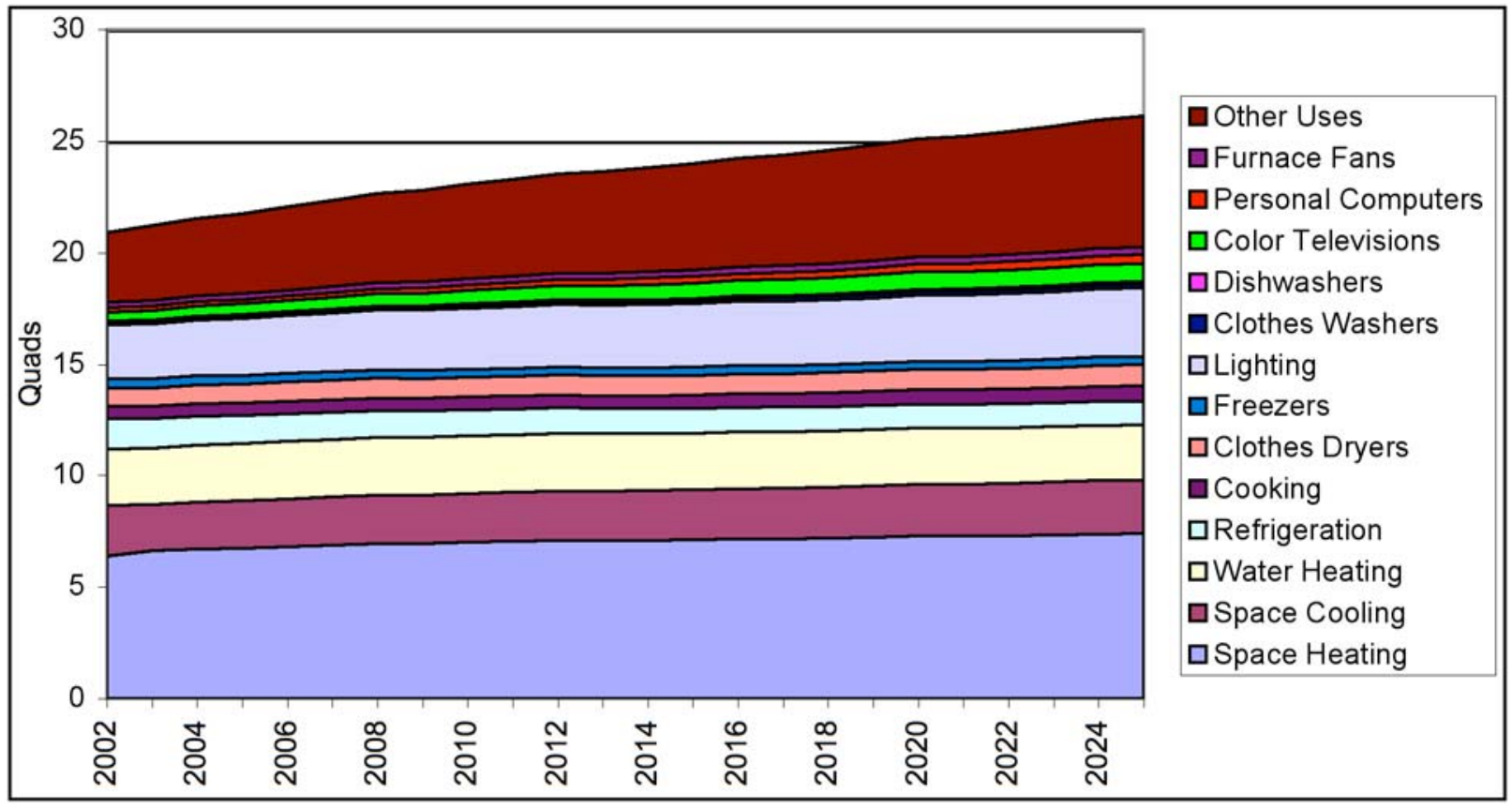

\footnotetext{
${ }^{1}$ The authors acknowledge the guidance and assistance of Dr. Marilyn Brown of Oak Ridge National Laboratory (ORNL) and board member of the National Commission on Energy Policy (NCEP). We also thank Sasha Mackler of the NCEP for his help in the logistics involved in creating this report. Several ORNL personnel assisted in providing information: Jeff Christian, John Shonder, Jim Hardy, and Patrick Hughes. Erin Boedecker of the Energy Information Administration provided information on the National Energy Modeling System. Lastly, Ernst Worrell, Lynn Price, and Christina Galitsky were very helpful as they worked on the companion report to this paper, Emerging Energy-Efficient Technologies in Industry: Technology Characterizations for Energy Modeling (Worrell, et al., 2004).
} 
Figure 2. AEO2004 Reference case commercial primary energy use (EIA 2003)

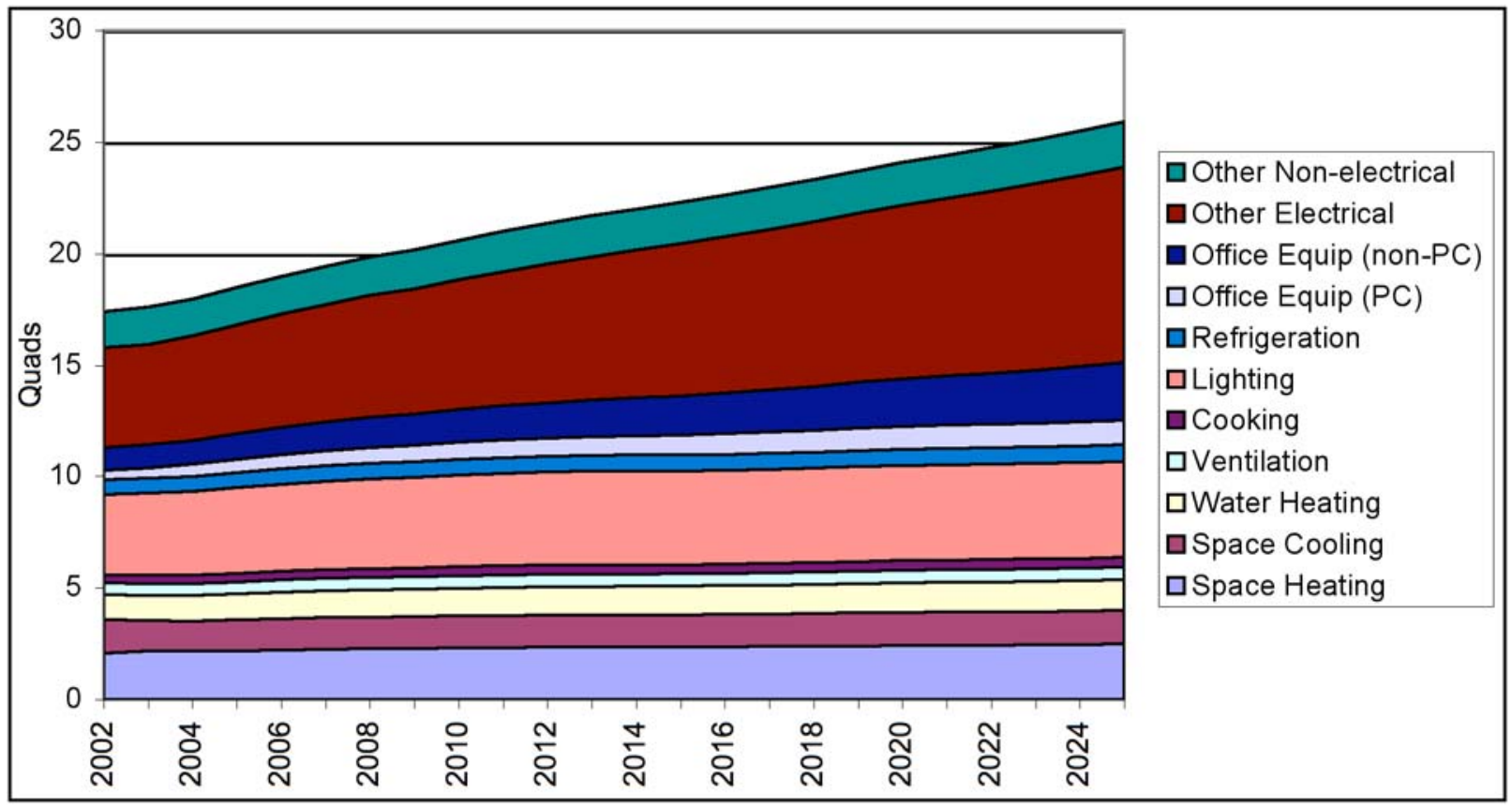

In the residential sector, the largest current demands are in space heating and cooling, water heating, and lighting. These are also the largest single end-uses in the commercial sector. The Other categories cover the multitude of other energy uses in homes and businesses, from toasters to swimming pool heaters, ATMs to elevators. Combined heat and power is included in the commercial other non-electrical use. As modeled in NEMS, these "Other" end-uses are less responsive to efficiency improvements and come to dominate each sector's energy use.

The five technologies described in this paper and achievable energy savings by 2025 are:

\section{- Solid state lighting}

- Inorganic and organic light emitting diodes that replace incandescent and fluorescent lighting in a broad variety of end-uses (1.2-3.5 Quads),

- Advanced geothermal heat pumps

- Selective water sorbents and other technologies that greatly reduce the capital cost and land requirements for geothermal heat pumps in residential and commercial sectors ( 0.2 Quads),

- Integrated energy equipment

- Multi-function (cooling, heating, hot water, dehumidification) and packaged combined heat and power technologies that integrate multiple energy services into single pieces of equipment to lower cost and increase efficiency ( 0.3 Quads),

- Efficient operations technologies

- Information technologies to improve the functioning of energy-using equipment on an ongoing basis within buildings ( 0.1 Quads), and

- Smart roofs

- Nano- and micro-technologies that change the reflectance and infra-red emissivity of roof materials as a function of temperature to retain heat in winter and reflect heat in summer (0.1 Quads). 
Summing these achievable savings gives a total of 1.9-4.2 Quads, which represents 4\%-8\% of projected 2025 residential and commercial demands of 52 Quads. The technical potential by 2025 from these technologies is much higher, 9.6 Quads, but does not factor in the time necessary for penetration of the market. The calculations of energy savings are only rough estimates using different methodologies. Many of the needed advances have not been developed yet and require further research. To some extent, these technologies will overlap and so savings may be less, but also the calculations only consider a subset of the possible market. The actual energy savings that will come will take time to achieve and are dependent on the amount of research and market penetration that occurs. It is hoped that through research and policy initiatives, these and other energy efficient technologies can play a major role in reducing the energy needs of our country.

\section{References}

EIA (Energy Information Administration) 2003, Annual Energy Outlook 2004: With Projections to 2025, DOE/EIA-0383 (2004) Washington, DC: U.S. Department of Energy, December.

< http://www.eia.doe.gov/oiaf/aeo/index.html.>

Nadel, Steven, Leo Rainer, Michael Shepard, Margaret Suozzo, Jennifer Thorne 1998 Emerging Energy-Saving Technologies and Practices for the Building Sector, American Council for an Energy Efficient Economy, October.

Worrell, Ernst, Lynn Price, and Christina Galitsky 2004, Emerging Energy-Efficient Technologies in Industry: Technology Characterizations for Energy Modeling, LBNL-54828, Lawrence Berkeley National Laboratory, May. 


\section{Solid State Lighting}

\subsection{Technology}

Solid-state lighting (SSL) has the potential to revolutionize the lighting market through the introduction of highly energy efficient, longer-lasting and more versatile light sources. Advancements in SSL technology over the last two decades have contributed to a gradual market penetration in colored and some specialty white-light markets. As industry and government investment continues to improve the performance and reduce the costs associated with this technology, SSL is expected to start competing with conventional light sources for market share in general illumination applications. The scientific and research communities forecast that as the performance of light emitting diodes (LEDs) and organic light emitting diodes (OLEDs) improves, their costs will simultaneously decrease. Energy savings will result from consumers choosing SSL sources in general illumination (white-light) applications such as offices, retail establishments and homes.

\subsubsection{Brief description}

SSL uses the emission of semi-conductor diodes to directly produce light, rather than resistance heating of a wire as in incandescent lamps or excitation of a gas as in fluorescent lamps. Electrons and holes are injected into a solid-state semiconductor material. When these recombine, light is emitted at around the wavelength corresponding to the energy bandgap of the material. Once the light is created internally, a high fraction of it must reach the surface and escape rather than be absorbed; this is done either through the shape of the LED or the type of material used. Because these lights can concentrate their emissions in the visible spectrum, they can be very efficient. Different wavelengths can be easily created by using different materials. However, SSL faces the problem that a single LED does not fill the full spectrum and appears colored. Creating a white, general-purpose light causes additional complexity and/or lower efficiency.

There are two main categories of lights: LED and OLED. LED lighting uses inorganic semiconductor material such as InGaN (ultra-violet), AlGaN (blue or green), AlInGaP (redorange), or AlGaAs (red), as well as others. It was first discovered in 1907 and the first commercial devices were introduced in 1968. OLED lighting uses organic polymers and provides a more diffuse lighting that may be more useful for displays for computers, televisions, or cell phones.

\subsubsection{End-uses}

Lighting has a wide variety of end-uses, from high-quality task lighting in residential buildings, to factory lighting for a large area, to street lighting, to warning signals and headlights in transportation, among others. There are a number of lighting attributes that define the attractiveness of a technology.

- Color Rendering Index (CRI) - how broad a spectrum the light provides for color rendition,

- Luminous efficacy $(\mathrm{lm} / \mathrm{W})$ - how much light (lumens) is provided for the power used,

- Lifetime (khr) - how long the lamp lasts,

- Flux (lm/lamp) - how much light each lamp provides, 
- $\operatorname{Cost}(\$ / \mathrm{klm})-$ Cost to consumer.

The CRI segregates end-uses by the quality of light required; e.g., street lighting does not need to provide good rendition of colors, but must provide sufficient low-cost light to make roadways visible. Navigant conducted two energy savings studies: one of general-purpose lighting (Navigant 2003a) and one of niche applications (Navigant 2003b). The general-purpose lighting study considered alternative SSL investment scenarios and compared the SSL to a variety of conventional lighting sources. They segregated the markets into four CRI bins as shown in Table 1 with typical lamps and purposes for each. While CRI is not the sole distinguishing characteristic, it does capture the fundamental differences in lighting services.

Table 1. CRI Bins and typical lamps and end-uses for each (Navigant 2003a)

\begin{tabular}{|c|c|c|c|}
\hline CRI Bin & CRI Range & Example Lamps & Example Purposes \\
\hline Low CRI & $0-40 \mathrm{CRI}$ & $\begin{array}{c}\text { Mercury Vapor, High } \\
\text { Pressure Sodium }\end{array}$ & Street lighting \\
\hline Medium CRI & $41-75 \mathrm{CRI}$ & $\begin{array}{c}\text { T12 four foot, T8 greater } \\
\text { than 4 foot, Circline }\end{array}$ & Warehouse, factory \\
\hline High CRI & $76-90 \mathrm{CRI}$ & $\begin{array}{c}\text { T8 four foot, Compact } \\
\text { Fluorescent Lamps }\end{array}$ & Office, commercial \\
\hline Very High CRI & $91-100 \mathrm{CRI}$ & Incandescent, Halogen & Residential \\
\hline
\end{tabular}

Other attributes, such as energy use or total cost per lamp, are shown in Table 2. These come from the Optoelectronics Industry Development Association Technology Roadmap (OIDA 2002a). They show current values and targets for LED lighting as well as representative values for some forms of incandescent and fluorescent lighting. The last two columns do not represent all forms of incandescent and fluorescent lighting; these can have a wide array of values depending on the specific purpose.

Table 2. SSL-LED Lamp Targets (OIDA Technology Roadmap Tutorial 2002)

\begin{tabular}{|l|c|c|c|c|c|c|}
\hline \multicolumn{1}{|c|}{ TECHNOLOGY } & $\begin{array}{c}\text { SSL-LED } \\
2002\end{array}$ & $\begin{array}{c}\text { SSL-LED } \\
2007\end{array}$ & $\begin{array}{c}\text { SSL-LED } \\
2012\end{array}$ & $\begin{array}{c}\text { SSL-LED } \\
2020\end{array}$ & Incandescent & Fluorescent \\
\hline Luminous Efficacy $(\mathrm{Im} / \mathrm{W})$ & 25 & 75 & 150 & 200 & 16 & 85 \\
\hline Lifetime $(\mathrm{khr})$ & 20 & $>20$ & $>100$ & $>100$ & 1 & 10 \\
\hline Flux (Im/lamp) & 25 & 200 & 1,000 & 1,500 & 1,200 & 3,400 \\
\hline Input Power $(\mathrm{W} / \mathrm{lamp})$ & 1 & 2.7 & 6.7 & 7.5 & 75 & 40 \\
\hline Lumens Cost $(\$ / \mathrm{klm})$ & 200 & 20 & $<5$ & $<2$ & 0.4 & 1.5 \\
\hline Lamp Cost $(\$ / \mathrm{lamp})$ & 5 & 4 & $<5$ & $<3$ & 0.5 & 5 \\
\hline Color Rendering Index (CRI) & 75 & 80 & $>80$ & $>80$ & 95 & 75 \\
\hline Lighting Markets Penetrated & Low-flux & Incandescent & Fluorescent & All & & \\
\hline
\end{tabular}

Initial end-uses for LED lighting have been in areas where long life has been especially desirable while high flux is not necessary (i.e., the light needs to be visible itself, but not necessarily illuminate other objects.) Examples include traffic lights, exit signs, and automobile taillights. In addition, these end-uses are generally single-color applications rather than white light so that CRI is not important.

Future applications will expand as the technology provides increased brightness, better CRI, longer life, and lower cost, as shown in Table 2. Initial applications will likely be in areas with little requirement for a high CRI such as outdoor and warehouse lighting. As the technology 
develops, with improved lighting quality and lowered cost, additional end-uses will be feasible. Eventually, most major end-uses could be supplied by LEDs.

OLEDs are most suitable in the near term for displays such as computer monitors or televisions. They may also be used for commercial accent lighting such as signs. In the longer term, they may be replacements for area lighting such as ceiling lights. However, the research priorities for the near-term end-uses (brightness, responsiveness) do not necessarily match the improvements needed for broader markets (efficiency, cost).

\subsubsection{R\&D needed}

A key difficulty that LED lighting faces is that it is inherently monochromatic. Different colors of LED's have been produced: red, green, yellow, orange, blue, and even ultra-violet. Three methods to produce white light have been developed, each with its advantages and disadvantages (Figure 3).

Figure 3. Possible approaches to white light production (Roadmap Update Tutorial / Nakamura 2002 and Martin 2002)

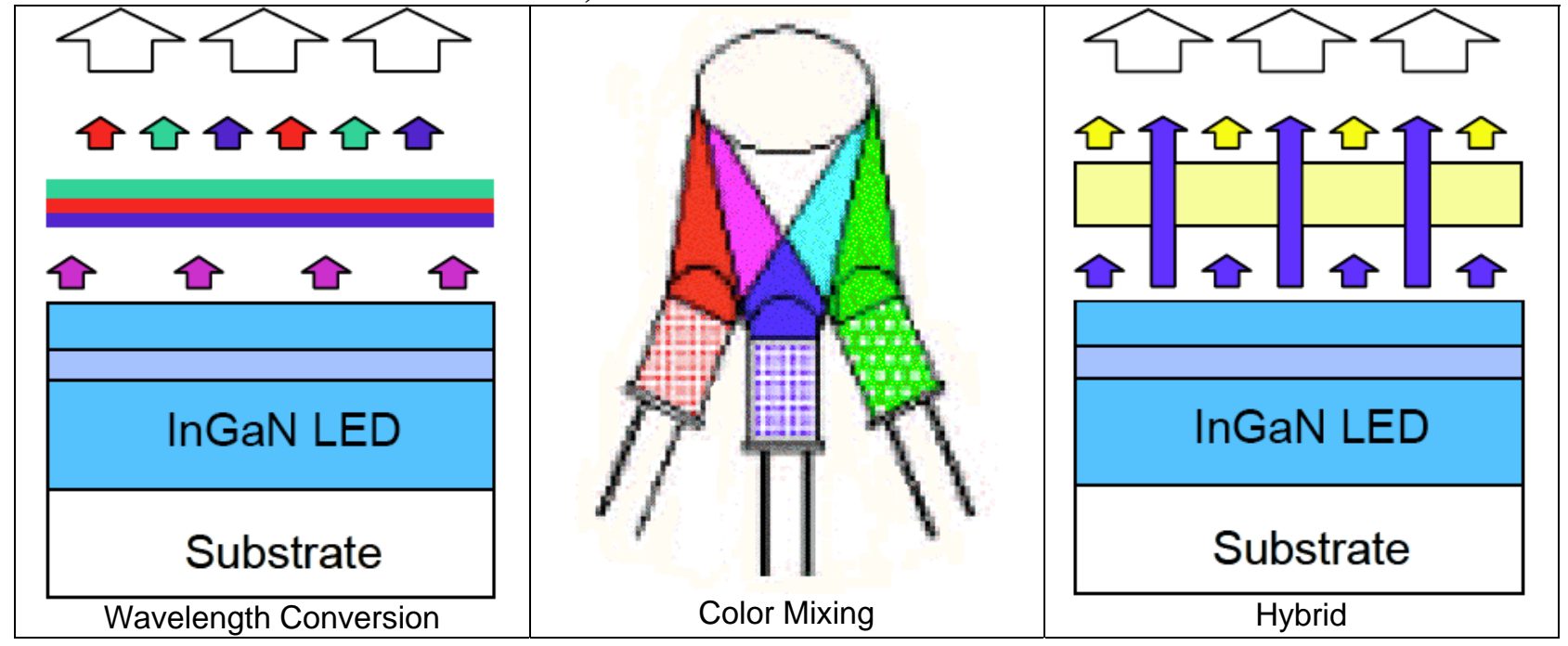

- Wavelength conversion involves using an ultra-violet LED with a three-color phosphor to down-convert the wavelength to a mixture of colors giving a white spectrum, similar to a fluorescent lamp. It is likely to be lowest cost of the three methods since it uses only one LED and colors are created together, easing engineering. However, it is also the most inefficient because of the losses during the down-conversion.

- Color mixing involves using three separate LEDs to provide white light, similar to television displays. It provides color flexibility by adjusting the output of each LED and has higher efficiency since no filters are needed. However, the three different LEDs add to the complexity and cost.

- A hybrid system uses a blue LED that has part of its light downshifted to its complement color of yellow, resulting in a perceived white light. However, the quality of the light is poor. Using only two colors gives a poorer CRI, and a "halo" effect occurs where the light directly from the lamp looks blue because it is directional while the yellow is more 
diffuse. Variations on this approach may improve the quality by using a two-color phosphor (from blue to red and green) or a green phosphor plus an additional red LED. The hybrid approach will have costs, complexity, and efficiencies in between the other two approaches.

For SSL to succeed in the market place there are a number of issues requiring research. The DOE/OIDA roadmapping exercise has identified additional long-term research in eight main areas (OIDA 2002b):

Materials research and the physics of light generation - Long term research should focus on the development of new experimental techniques, complete characterization of materials and devices, detailed first principles modeling, and the development of new semiconductor materials and device structures.

Substrate materials - There are at least three different substrate materials used: sapphire, GAN, and $\mathrm{SiC}$. Each has its pros and cons but none provide a large area, defect-free substrate with good lattice match and at a reasonable cost

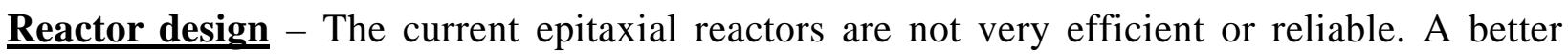
understanding of the chemical reactions for the growth of nitride materials and reactor fluid dynamics should enable more efficient and robust reactors.

Light extraction - Due to the high refractive index of LED material a large fraction of the light is trapped inside the LED. Research in materials, architecture, and modeling of light extraction are necessary.

Photon conversion materials - Conversion of ultraviolet to visible light and compatibility of phosphors under LED lighting conditions should be explored. Novel wavelength conversion materials and encapsulents that are insensitive to radiation would help in the production of longlived LEDs.

Novel concepts of solid-state light emission - Research can expand the types of SSL beyond LEDs. These could include novel device structures, super luminescent diodes, edge emitters, or other concepts such as quantum dots or photonic lattices.

Packaging - This topic was identified as having an enormous impact on the efficiency, life, and cost of LED devices, but must first be led by the final LED design strategies.

Lighting infrastructure - Only a third of the $\$ 40$ billion in lighting represents light bulbs. The larger market includes lighting fixtures, powering, distribution, etc. Research in these other aspects of the industry so that they better utilize SSL will help SSL succeed in the market.

Understanding materials issues with both the semiconductor and the substrate are crucial to improving efficiency and lowering cost. These research areas over the next five years should help to make SSL into a commercially viable industry. 


\subsection{Cost}

The cost of LED technologies is currently too high to compete with general service types of lighting, but with accelerated investment in $R \& D$, future penetration could occur. Table 2 from the OIDA Technology Roadmap Update shows an estimate of present and future costs for SSLLED. While the initial lamp cost is expected to stay higher than for incandescent or fluorescent lighting, the longer life and higher efficiency should lower the lifecycle cost per lumen-hour (Table 3, OIDA 2002a). The table shows that on an over-all ownership cost per lumen-hour, SSL could surpass incandescent lighting by 2007 and fluorescent lighting by 2012. However, on an initial cost per lumen (ignoring the lifetime of the lamp) the SSL cost remains higher (Table 4). Quality aspects such as CRI only determine where SSL can compete, cost objectives determine if it will compete. Total costs include the capital costs and operating costs of the technology. The cost comparisons should also include such factors as maintenance and replacement costs to equalize the total lighting service over its lifetime.

Table 3. Purchase and operating costs associated with traditional lamps and SSL-LED target lamps (OIDA Technology Roadmap Tutorial 2002a)

\begin{tabular}{|l|c|c|c|c|c|c|}
\hline \multicolumn{1}{|c|}{ COST OF LIGHT } & SSL-LED & SSL-LED & SSL-LED & SSL-LED & Incandescent & Fluorescent \\
& 2002 & 2007 & 2012 & 2020 & & \\
\hline Capital Cost $(\$ / \mathrm{Mlm}-\mathrm{hr})$ & 12.00 & 1.25 & 0.30 & 0.13 & 1.25 & 0.18 \\
\hline Operating Cost $(\$ / \mathrm{Mlm}-\mathrm{hr})$ & 4.00 & 1.33 & 0.67 & 0.50 & 6.25 & 1.18 \\
\hline Total Cost $(\$ / \mathrm{Mlm}-\mathrm{hr})$ & 16.00 & 2.58 & 0.97 & 0.63 & 7.50 & 1.35 \\
\hline
\end{tabular}

Navigant conducted two energy savings studies: one of general-purpose lighting and one of niche applications. The general purpose lighting study (Navigant 2003a) considered alternative SSL investment scenarios and compared the SSL to a variety of conventional lighting sources. They segregated the markets into the four CRI bins of Table 1 and four sectors: residential, commercial, industrial, and outdoor. For these markets they proposed a moderate and accelerated investment in SSL R\&D. Table 4 shows the lamp price, efficacy, and life of the four LED market segments, along with expected values for some of the conventional commercial lights.

The steps involved in the Navigant general-purpose lighting study included:

1. Determine lighting demand converting data from DOE on the lighting market into lumen hours of lighting service;

2. Group similar lighting types as shown in Table 1;

3. Project lighting demand using new building construction projections from the Annual Energy Outlook 2003 (EIA 2003a);

4. Create an adjustable stock-model to determine lighting "turn-over";

5. Estimate improvements in cost, efficacy and operating life of conventional technologies;

6. Estimate improvements in cost, efficacy and operating life of SSL technologies;

7. Project lighting costs based on current markets and anticipated cost improvements in installation and operation; 
8. Develop an economic model of the U.S. lighting market to calculate SSL market penetration based on relative costs;

9. Calculate energy savings based on SSL performance and market penetration.

Table 4. Projected price, efficacy, and life for SSL with accelerated investment compared to conventional lighting (Navigant 2003a)

\begin{tabular}{|l|c|c|c|c|c|c|}
\hline \multicolumn{1}{|c|}{ Light and CRI } & \multicolumn{2}{c|}{ Lamp Price (\$/klumen) } & \multicolumn{2}{c|}{$\begin{array}{c}\text { Efficacy (lumens per } \\
\text { watt) }\end{array}$} & \multicolumn{2}{c|}{ Life (thousand hours) } \\
\hline & 2005 & 2025 & 2005 & 2025 & 2005 & 2025 \\
\hline Low CRI LED, 0-40 & 32.8 & 1.2 & 90.3 & 225.6 & 30.8 & 99.9 \\
\hline Med CRI LED, 41-75 & 81.2 & 2.5 & 65.5 & 181.5 & 18.6 & 99.9 \\
\hline High CRI LED, 76-90 & 145.9 & 3.3 & 47.1 & 162.3 & 15.7 & 99.8 \\
\hline Very High CRI LED, 91-100 & 230.8 & 5.8 & 24.7 & 142.3 & 12.4 & 99.6 \\
\hline $\begin{array}{l}\text { General Service Incandescent, } \\
\text { 100 CRI }\end{array}$ & 0.86 & 0.72 & 14 & 15 & 2.5 & 2.8 \\
\hline T8 Fluorescent, 68 CRI & 0.73 & 0.60 & 83 & 91 & 17.5 & 21 \\
\hline High Pressure Sodium, 22 CRI & 0.85 & 0.63 & 100 & 120 & 20 & 24 \\
\hline
\end{tabular}

While initial lamp cost is higher per thousand lumens, the LEDs have a target life of over four times the life of efficient competitors and thirty times the life of incandescents.

\subsection{Energy}

\subsubsection{Energy consumption and comparison to existing}

Energy use of SSL lighting will depend on the application and type of SSL used. The Navigant general purpose lighting study (Navigant 2003a) considered alternative SSL investment scenarios and compared the SSL to a variety of conventional lighting sources. Their accelerated investment scenario assumed a national investment of $\sim \$ 100$ million per year, which is high but achieved significantly improved performance and reduced cost (Table 4). Their moderate investment scenario did not advance technologies as much, with medium CRI LEDs achieving $93 \mathrm{~lm} / \mathrm{W}$ and $\$ 4.3 / \mathrm{klm}$ by 2025 .

Monochromatic, niche end-uses show great efficiency savings compared to existing technologies and their long life greatly reduces maintenance costs. To create single color lighting from incandescent lights requires filtering out of most of the output. For example, in a 12" traffic signal, an $11 \mathrm{~W}$ LED red signal head replaces a $140 \mathrm{~W}$ reflector lamp resulting in a $92 \%$ reduction in energy consumption (Navigant 2003b). This is why LEDs have penetrated most significantly in niche markets such as exit signs, traffic lights, and large truck and bus lights (Table 5, Navigant 2003b). Total primary energy savings in the niche markets in 2002 were 0.116 Quads (116 TBtu), and the potential savings if all niche lighting changed to LED was estimated at 0.554 Quads. 
Table 5. Energy Consumption and Savings in 2002 of Niche Markets Evaluated (Navigant 2003b)

\begin{tabular}{|l|c|c|c|c|}
\hline Application & $\begin{array}{c}\text { Annual } \\
\text { Energy }\end{array}$ & $\begin{array}{c}\text { LED Market } \\
\text { Penetration }\end{array}$ & $\begin{array}{c}\text { Electricity } \\
\text { Savings 2002 }\end{array}$ & $\begin{array}{c}\text { Primary Energy } \\
\text { Savings 2002 }\end{array}$ \\
\hline Mobile Transportation Applications & $12.95 \mathrm{TWh}$ & $1-2 \%$ & $0.17 \mathrm{TWh}$ & $\begin{array}{c}41.3 \mathrm{Mgal} \text { gasoline } \\
(4.9 \mathrm{TBtu})\end{array}$ \\
\hline Automobile Lights & $11.80 \mathrm{TWh}$ & $5-7 \% / 41 \%$ & $1.07 \mathrm{TWh}$ & $\begin{array}{c}142.1 \mathrm{Mgal} \text { diesel } \\
(19.9 \mathrm{TBtu})\end{array}$ \\
\hline Large Truck and Bus Lights & $0.003 \mathrm{TWh}$ & $0 \%$ & $0.0 \mathrm{TWh}$ & $0.0 \mathrm{gal} \mathrm{jet} \mathrm{(0.0} \mathrm{TBtu)}$ \\
\hline Aircraft Passenger Lights & $3.41 \mathrm{TWh}$ & $30 \%$ & $1.48 \mathrm{TWh}$ & $16.2 \mathrm{TBtu}$ \\
\hline Stationary Transportation Applications & $0.025 \mathrm{TWh}$ & $3-4 \%$ & $0.001 \mathrm{TWh}$ & $0.007 \mathrm{TBtu}$ \\
\hline Traffic Signals & $0.06 \mathrm{TWh}$ & $1-1.5 \%$ & $0.001 \mathrm{TWh}$ & $0.007 \mathrm{TBtu}$ \\
\hline Railway Signals & \multicolumn{3}{|c|}{} \\
\hline Airport Taxiway Edge Lights & $2.57 \mathrm{TWh}$ & $80 \%$ & $6.86 \mathrm{TWh}$ & $75.2 \mathrm{TBtu}$ \\
\hline Other Stationary Applications & $2.22 \mathrm{TWh}$ & $0 \%$ & $0.0 \mathrm{TWh}$ & $0.0 \mathrm{TBtu}$ \\
\hline Exit Signs & $10.06 \mathrm{TWh}$ & $0 \%$ & $0.0 \mathrm{TWh}$ & $0.0 \mathrm{TBtu}$ \\
\hline Holiday Lights & $43.1 \mathrm{TWh}$ & - & $9.6 \mathrm{TWh}$ & $116.1 \mathrm{TBtu}$ \\
\hline Commercial Advertising Signs
\end{tabular}

\subsubsection{Potential energy savings}

The lighting demands for the four CRI segments in each sector (in teralumen-hours) are shown in Table 6 . Annual growth rates are expected in the $1 \%$ to $1.5 \%$ range.

Table 6. Sector and CRI Bins of Teralumen-hours Lighting Demand in 2005 (Navigant 2003a)

\begin{tabular}{|c|rrrrr|}
\hline CRI Bin & Residential & Commercial & Industrial & Outdoor & CRI-Bin Total \\
\hline Low CRI & 33 & 1,021 & 711 & 4,145 & 5,910 \\
Medium CRI & 1,336 & 12,451 & 3,755 & 572 & 18,113 \\
High CRI & 62 & 7,932 & 4,258 & 64 & 12,316 \\
Very High CRI & 2,632 & 1,956 & 41 & 88 & 4,717 \\
\hline Sector Totals & 4,062 & 23,361 & 8,765 & 4,868 & 41,056 \\
\hline
\end{tabular}

Lighting services are most demanded in the commercial sector, especially for medium and high CRI lighting such as that provided by fluorescent lighting. According to the AEO2004 (EIA 2003b), lighting is the largest electrical end-use for both residential and commercial sectors, and the largest single energy use in the commercial sector (Figure 1 and Figure 2 in the Introduction.)

Energy savings projections in the general illumination markets using Navigant's investment scenarios are shown in Table 7 . As much as $33 \%$ of reference energy use for lighting could be saved in the accelerated investment scenario by 2025. Navigant calculated these values using the methodology described in Section 2.2 above.

Table 7. Primary energy used and savings for moderate and accelerated LED R\&D investment, Quads (Navigant 2003a)

\begin{tabular}{|l|c|c|c|c|c|}
\hline & $\mathbf{2 0 1 0}$ & $\mathbf{2 0 1 5}$ & $\mathbf{2 0 2 0}$ & $\mathbf{2 0 2 5}$ & Cumulative \\
\hline Reference case energy used & 9.24 & 9.68 & 10.08 & 10.47 & n/a \\
\hline Moderate Investment savings & 0.00 & 0.04 & 0.39 & 1.23 & 5.44 \\
\hline Accelerated Investment savings & 0.01 & 0.34 & 1.67 & 3.51 & 19.9 \\
\hline
\end{tabular}




\subsection{NEMS approach}

NEMS models lighting in both the residential and commercial modules, but to different levels of detail. In the residential module, NEMS contains parameters for three standard lighting and two torchiere technologies. The capital cost for 2001, 2010 and 2020, wattage, and efficiency are built into the FORTRAN coding of the model, in the source code resd.f. Torchiere penetration rates over time are also built in. In the AEO2004, the values are shown in Table 8. The capital costs are not well-described but based on their use in the model they include the non-energy costs for six years' worth of bulbs as well as the lamp.

Table 8. Residential lighting parameters in NEMS for AEO2004 (EIA 2003b)

\begin{tabular}{|c|c|c|c|c|c|}
\hline Technology & Wattage & Efficiency, Im/W & $\begin{array}{c}\text { Capital Cost } \\
2001, \$ / \operatorname{lamp}\end{array}$ & $\begin{array}{c}\text { Capital Cost } \\
2010, \$ / \text { lamp }\end{array}$ & $\begin{array}{c}\text { Capital Cost } \\
2020, \$ / \text { lamp }\end{array}$ \\
\hline Standard 1 & 75 & 18 & 5.6 & 5.6 & 5.6 \\
\hline Standard 2 & 20 & 50.625 & 75 & 65 & 60 \\
\hline Standard 3 & 10 & 88 & 10000 & 10000 & 10000 \\
\hline Torchiere 1 & 300 & & 10 & 10 & 10 \\
\hline Torchiere 2 & 78 & & 75 & 70 & 65 \\
\hline
\end{tabular}

For standard lighting wattage is used for calculating operating costs and market share is determined by ratios of operating to capital costs logit parameters. Energy use is comparing the efficiency of the lighting relative to a base efficiency of 18. Torchiere energy use is based on the relative wattage of the two types of torchiere, with market share dependent on relative costs. SSL lighting could be put in through modification of the Standard 3 lighting technology, reducing the capital costs to roughly that of Standard 2, although this does not truly capture the differences over time in efficiency, lifetime and other characteristics of SSL.

In the commercial sector, lighting is modeled in more detail and with more flexibility. NEMS currently has 24 different lighting technologies, and can handle more. Efficiency, capital cost, operating cost, lifetime and state of technology all help to define the technologies over time. The commercial sector also only has costs change over time, not efficiency or other parameters. However, a start and end year for availability of each technology allows improvements to be introduced. Also, CRI market segments are not observed. Table 9 shows values for some of the representative technologies in the AEO2004.

Table 9. Example commercial lighting parameters in NEMS for the AEO2004 (EIA 2003b)

\begin{tabular}{|l|c|c|c|c|c|c|}
\hline \multicolumn{1}{|c|}{ Technology } & $\begin{array}{c}\text { Efficiency } \\
\text { Im/W }\end{array}$ & $\begin{array}{c}\text { Capital } \\
\text { Cost, } \$ / \mathrm{km}\end{array}$ & $\begin{array}{c}\text { O\&M Cost, } \\
\$ / \mathrm{klm}\end{array}$ & Life & Tech Type & $\begin{array}{c}\text { Cost } \\
\text { Decline }\end{array}$ \\
\hline Incandescent 1150 lumens, 75 watts & 15.3 & 15.3 & 15.3 & 12 & Mature & 0.0 \\
\hline High Pressure Sodium & 89.7 & 19.6 & 0.6 & 15.0 & Mature & 0.0 \\
\hline F32T8 -Electronic -Reflector & 88.3 & 27.0 & 0.7 & 13.9 & Adolescent & 0.1 \\
\hline CFL 1200 lumens, 20 watts & 67.1 & 61.5 & 7.2 & 12.0 & Adolescent & 0.1 \\
\hline
\end{tabular}

SSL can be represented by adding these technologies into the mix, using values from Table 2 or Table 4. Multiple SSL can be added with staggered windows of availability to represent changes in efficiency, cost, or life. 


\subsection{References}

EIA 2003a, Annual Energy Outlook 2003: With Projections to 2025, DOE/EIA-0383 (2003) Washington, DC: U.S. Department of Energy, January.

EIA 2003b, Annual Energy Outlook 2004: With Projections to 2025, DOE/EIA-0383 (2004) Washington, DC: U.S. Department of Energy, December.

$<$ http://www.eia.doe.gov/oiaf/aeo/index.html

Martin, Paul S. 2002 "Performance, Thermal, Cost and Reliability Challenges for Solid State Lighting," OIDA Solid-State Lighting Workshop, Albuquerque, NM, May 30.

Nakamura, Shuji, 2002, "Status of GaN LEDs and Lasers for Solid-State Lighting and Displays," OIDA Solid-State Lighting Workshop, Albuquerque, NM, May 30.

Navigant 2003a, Energy Savings Potential of Solid State Lighting in General Illumination Applications, Navigant Consulting, Washington DC, November <http://www.netl.doe.gov/ssl/PDFs/SSL\%20Energy\%20Savi_ntial\%20Final.pdf>

Navigant 2003b, Energy Savings Estimates of Light Emitting Diodes in Niche Lighting Applications, Navigant Consulting, Washington DC, November <http://www.netl.doe.gov/ssl/PDFs/Niche\%20Final\%20Report.pdf>

OIDA 2002a, Light Emitting Diodes (LEDs) for General Illumination: An OIDA Technology Roadmap Update 2002, Optoelectronics Industry Development Association, Washington DC, November.

<http://www.netl.doe.gov/ssl/workshop/Report\%20led\%20November\%202002a_1.pdf〉

OIDA 2002b, The Promise of Solid State Lighting for General Illumination: 2002 Update, Optoelectronics Industry Development Association, Washington DC.

<http://lighting.sandia.gov/lightingdocs/OIDA_SSL_Roadmap_Summary_2002.pdf> 


\section{Advanced Geothermal}

\subsection{Technology}

Space heating and cooling are provided by a variety of technologies across the United States. Cooling is provided largely through central or room air conditioning systems while heating is provided largely through direct combustion of natural gas, LPG, or oil. Heat pumps are also used for heating (and cooling), but provide less than $10 \%$ of the heating needs in the country. A heat pump works on the same principle as an air conditioner except that it allows the functions of the evaporator and condenser (which absorb and reject heat) to be exchanged depending on whether heating or cooling is required.

Heat pumps have been around for many years, and the technology is quite robust. However, they suffer from one problem. The efficiency and capacity of heat pumps depends on the temperature difference across which the heat is to be pumped: the greater this temperature difference, the lower the efficiency and the lower the capacity. For an air-source heat pump, the temperature difference corresponds to the difference between outside air temperature and the desired indoor air temperature. Thus in the cooling season, both the cooling capacity and the cooling efficiency decrease as the outdoor air temperature rises. Likewise, in the heating season, both the heating capacity and the heating efficiency decrease as outdoor air temperature falls. In most applications, supplemental heating is required during the winter.

A geothermal heat pump (GHP) solves the problem of decreasing efficiencies due to temperature extremes by eliminating the outdoor coil altogether, and replacing it with a heat exchanger that is coupled to the earth. Unlike outdoor air temperatures - which can vary by more than $100^{\circ} \mathrm{F}$ over the year - the temperature of the earth just a few feet below the surface is fairly constant. Absorbing and rejecting heat to the earth results in a heat pump with higher efficiency and more stable capacity throughout the year. Most applications do not require supplemental heating. The main disadvantages of the conventional GHP systems relative to air-to-air heat pumps are the extra expense of burying heat exchangers in the earth and the difficulty of locating and making repairs, if needed.

Several near- and long-term technologies could improve the cost-effectiveness of GHP systems. One way of reducing the cost of GHPs is to use a supplemental heat rejecter such as a dry fluid cooler. In this type of system - known as a hybrid - the ground heat exchangers are typically sized to meet the heating load only. During the cooling season, some of the heat that would have been rejected to the ground is rejected to the atmosphere through the fluid cooler.

Recent research has identified a process that can overcome more of the shortfalls in conventional ground-coupled heat pumps and offer even higher efficiencies and peak load reduction capability for residential and small commercial heat pumps. The expense of large underground heat exchangers is bypassed by a revolutionary new process of heat recovery that enables a small heat exchanger with a special desiccant-like material to exchange water naturally present in the environment either in the form of humidity or as adsorbed water. The process is termed selective water sorbents (SWS). 
By absorbing water from the ambient surroundings (ground or air) during off-peak periods and desorbing water during peak periods, the overall energy profile can be changed to accomplish higher cooling efficiencies and simultaneously reduce peak electric demand. In a ground-coupled situation, the system would use a small, buried container that can rapidly exchange heat through a reversible process of exchanging water between the SWS and its environs (Figure 4). Since water has a large heat of vaporization, small quantities of water transport can move large amounts of energy across small thermal gradients.

Since water is environmentally benign, SWS technology offers both energy efficiency and environmental benefits. The dynamic sequence of water exchange reduces the footprint and physical size of a ground-coupled heat exchanger, lowering its initial and operating costs and increasing the potential market. Additional improvements may increase the likelihood of expansion of this energy efficient and green technology as the SWS technology is further developed.

\section{Figure 4. Schematic of SWS geothermal heat pump}

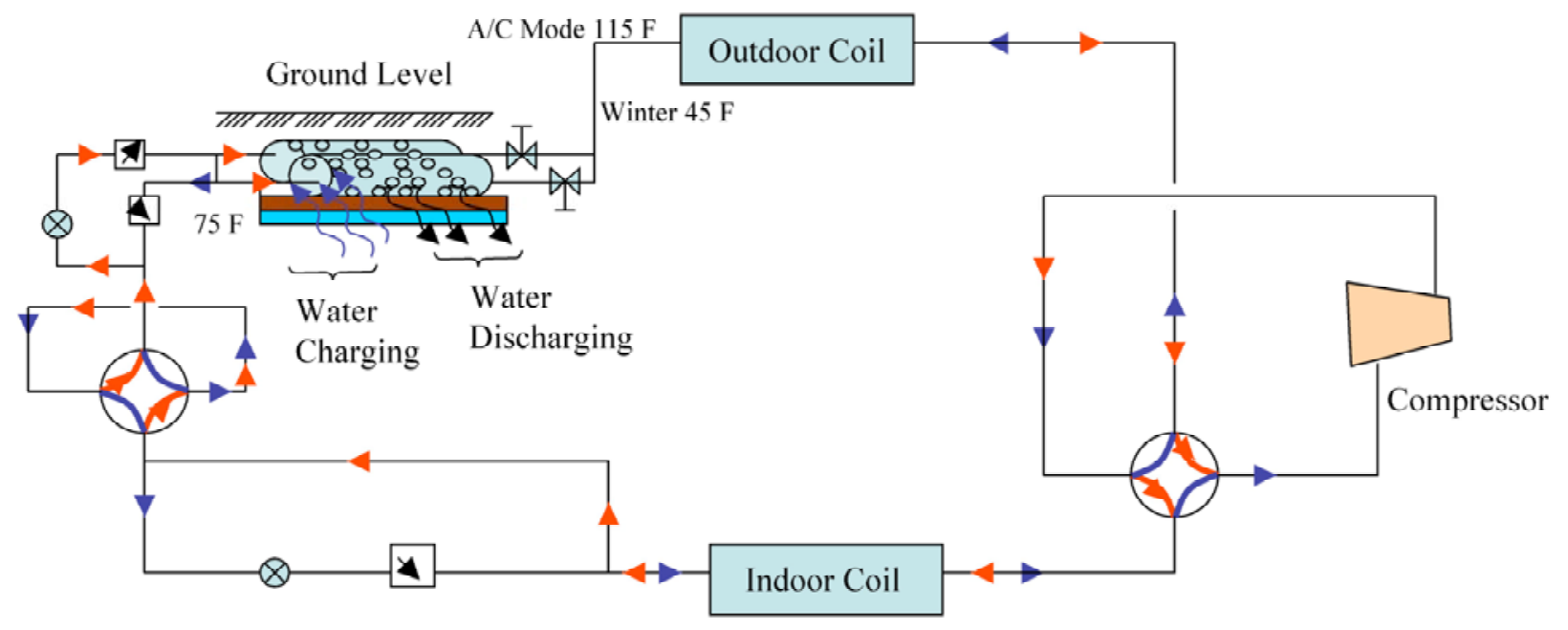

\subsubsection{Brief description}

SWS technology uses the difference in water vapor pressure between itself and the environment (ground or air) to transport water with a high latent heat of vaporization (Figure 5). SWS materials researched recently include open-pore mesoporous matrix substrate filled with a hygroscopic substance or a hydrated salt (Atistov, et al., 2002, Levitskij, et al, 1996). These materials are inexpensive, widely available, and manufactured in bulk quantities for a variety of industrial and commercial applications. An example of an open matrix substrate is Type A or RD silica gel and a typical hydrated salt is calcium chloride present as a tetra- or hexahydrate. Other SWS materials would be those that absorb up to 350 times their dry weight of water. These are also produced in bulk amounts and sold commercially. 


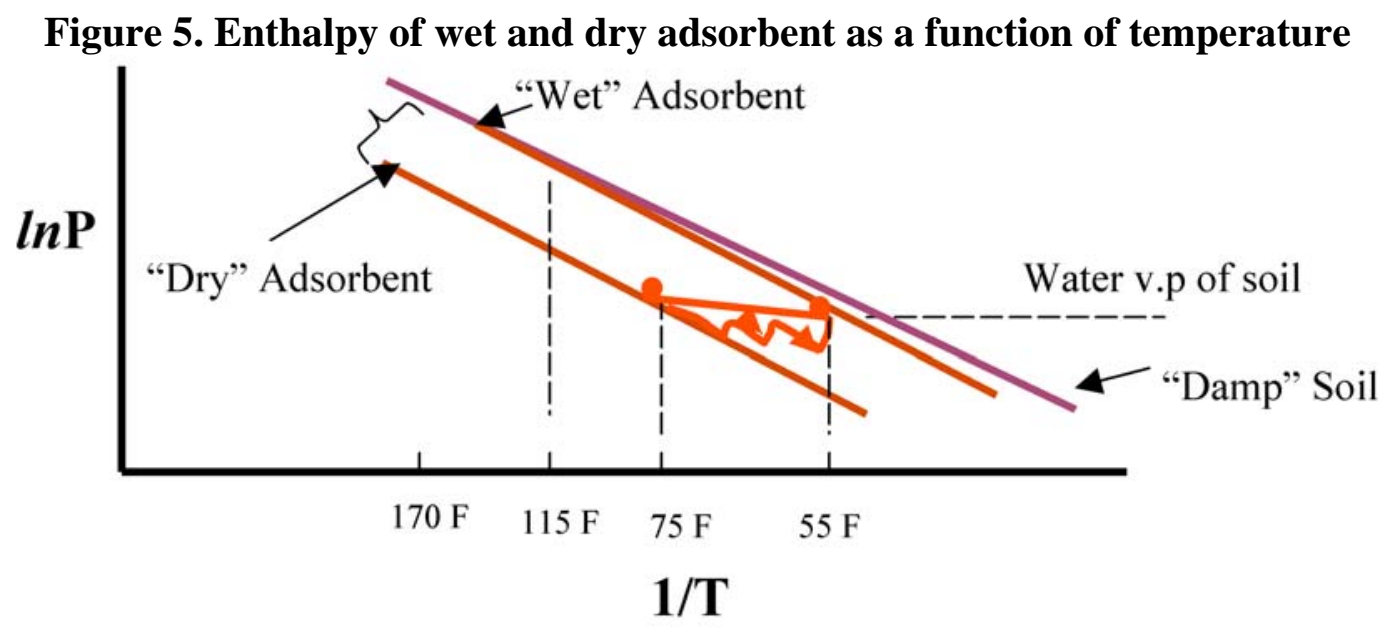

SWS also has the added property of being able to absorb about 7 to 8 times its own weight of water, thereby making water storage very efficient. Water is released when the temperature of the SWS is such that its water vapor pressure is slightly above the environment. Water is absorbed by the SWS when its temperature is slightly below that of its environment, or if it comes into contact with condensed water. European research has shown that these properties of SWS materials can be exploited for engineering a new generation of highly cost-effective and more efficient ground-coupled heat pumps that can also offer peak electricity demand reductions.

\subsubsection{End-uses}

For residential customers, the cost of a ground-coupled heat pump is about 4 times greater than the same-size air-to-air heat pump. In 1991, TVA initiated a program that offered customers of participating power distributors "free" ground loops. Two years later, only 219 customers were participating. The customer costs for a 3-ton heat pump unit was $\$ 5400$; TVA cost was $\$ 435$ and the distributor cost was $\$ 870$. Thus, the total cost for the ground-coupled heat pump system was $\$ 6705$ (or $\$ 2235 /$ ton) (Kavanaugh et al., 1995). These costs do not include any overhead and profit for the loop installation component since it was subsidized by the utility. A 3-ton air-to-air system would cost $\$ 4000$. At an estimated savings of $\$ 300 /$ year, simple payback was 4.7 years with the utility supplement and 9.0 years without. Kavanaugh et. al (ibid.) states that, "Many customers are very reluctant to participate in the program even with the 4.7 year payback. Since little activity has occurred without supplements, it is likely that very few customers would be eager to participate with the 9-year payback."

It is estimated that ground-coupled systems comprise less than $2 \%$ of HVAC sales in the United States. The main market impediments relate primarily to a lack of awareness and knowledge about the technology, its benefits and the high initial costs. Other barriers include lack of reliable installation and service infrastructure and its perception as an innovative and unconventional HVAC choice. For these reasons, ground-coupled systems constitute a higher risk decision for purchaser and seller, alike.

Development of the SWS would address many technical barriers facing ground-coupled heat pumps. With some investment incentives and the readiness of architectural and engineering communities to offer this energy saving and environmentally friendly technology as an option 
could enable greater market penetration in the future. Market penetration might be assisted with incentive plans for adopting environmentally friendly technologies and options offered by architects and builders.

\subsubsection{R\&D needed}

SWS technology is being hotly pursued throughout Europe [Aristov et al., (2002); Gordeeva, (1998a, 1998b); Cacciola (1994); Meunier, 1992; Shelton, (1992)], because of its potential use in ground-coupled, solar and sorption cooling/heating technologies and because it is completely consistent with the requirements of the Montreal Protocol of 1988 and with the Kyoto Protocol of 1997. Research and development is starting to address the following issues that will improve the viability of SWS as a phase change material (PCM) for use in heat pumps:

- Energy density of $1200 \mathrm{Btu} / \mathrm{lb}$ is possible, compared to 60-200 Btu/lb for known phase change materials.

- Phase transition at a sliding temperature between $-15^{\circ} \mathrm{C}$ up to $110^{\circ} \mathrm{C}$, which can fit any practical HVAC application.

- Not limited to one fixed temperature or to a narrow range of temperatures like traditional PCM blends. This adds flexibility to design and improved performance.

- Issues related to incongruent melting are non-existent. This is a significant drawback to traditional PCMs.

- Does not require energy to restore initial phase. This is the main limitation of the thermal ice storage concept.

- Improve the design of heat pump equipment using the SWS concept to fulfill DOE's objective of achieving SEER >20 for a 1 ton unit, with no maintenance for the SWS over the twenty year life of the equipment.

A prototype system can be ready for testing by FY 2006 with sufficient funding. Long-term, additional research is needed in the following three areas:

- The physics of SWS materials and types of chemical precursor materials that can be used for storage of water in condensed form;

- Routes of synthesis suitable for mass production;

- Improved understanding of physico-chemical processes and influence of aging on material properties.

\subsection{Cost}

Fortunately, the cost of SWS precursor materials is low and therefore from a material inventory standpoint the economics appear favorable. Some SWS materials are commercially available and can easily be modified to suit ground-coupled heat pump applications. Other SWS materials require synthesis and hence the costs associated with these steps need to be factored in the price. Figure 6 below shows the cost advantage of the ground-coupled portion of an SWS heat pump system compared against conventional ground-coupled systems available to the consumer. (Kavanaugh, et al., 1995) and preliminary in-house calculations on SWS based on literature. (Saha, et al. (2003); Chua et al, (1999); Chua, et al. (2004)). Since SWS precludes extensive excavation, it offers a very attractive installed cost structure to the consumer. Full-cost of a system would also include the 
Figure 6. Installed cost of SWS vs. traditional ground-coupled heat pumps

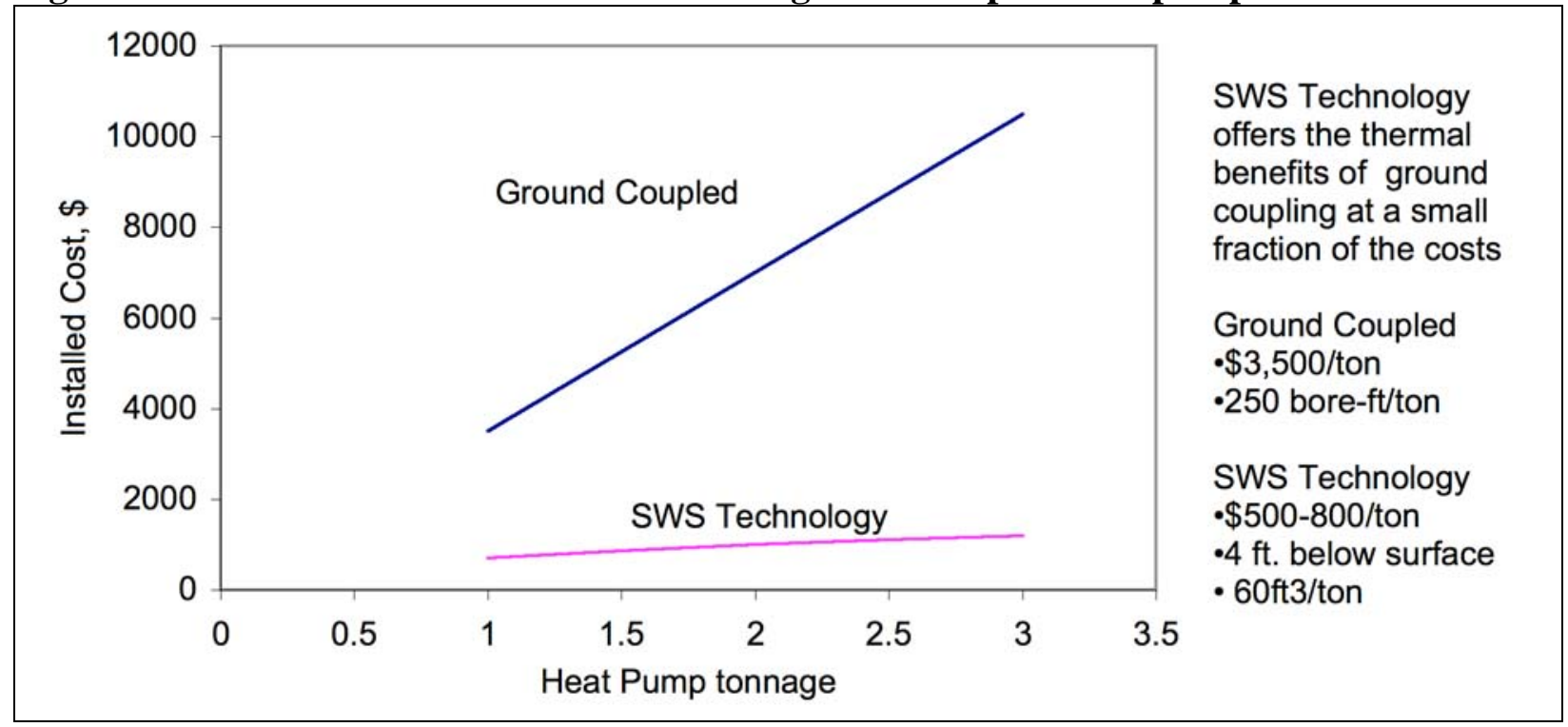

\subsection{Energy}

\subsubsection{Energy consumption and comparison to existing technology}

Simulation studies indicate energy as well as peak electric demand reduction using SWS in a ground-coupled heat pump in residential applications. A comparison of the aggregate electric demand in DOE's Region III, (the Mid-Atlantic states of New Jersey, Pennsylvania, Delaware, Maryland, Virginia, and West Virginia) depicting electricity savings during the summer (daytime cooling) and winter (night time heating) as a function of the ambient temperature is shown below (Figure 7) (Rice, 2004). These calculations were made using the DOE/ORNL Heat Pump Design Model for DOE Region III. (DOE 2004)

Figure 7. Comparison of aggregate demand between SWS and Air-to-Air HPs: Heating (nighttime) and Cooling (daytime)
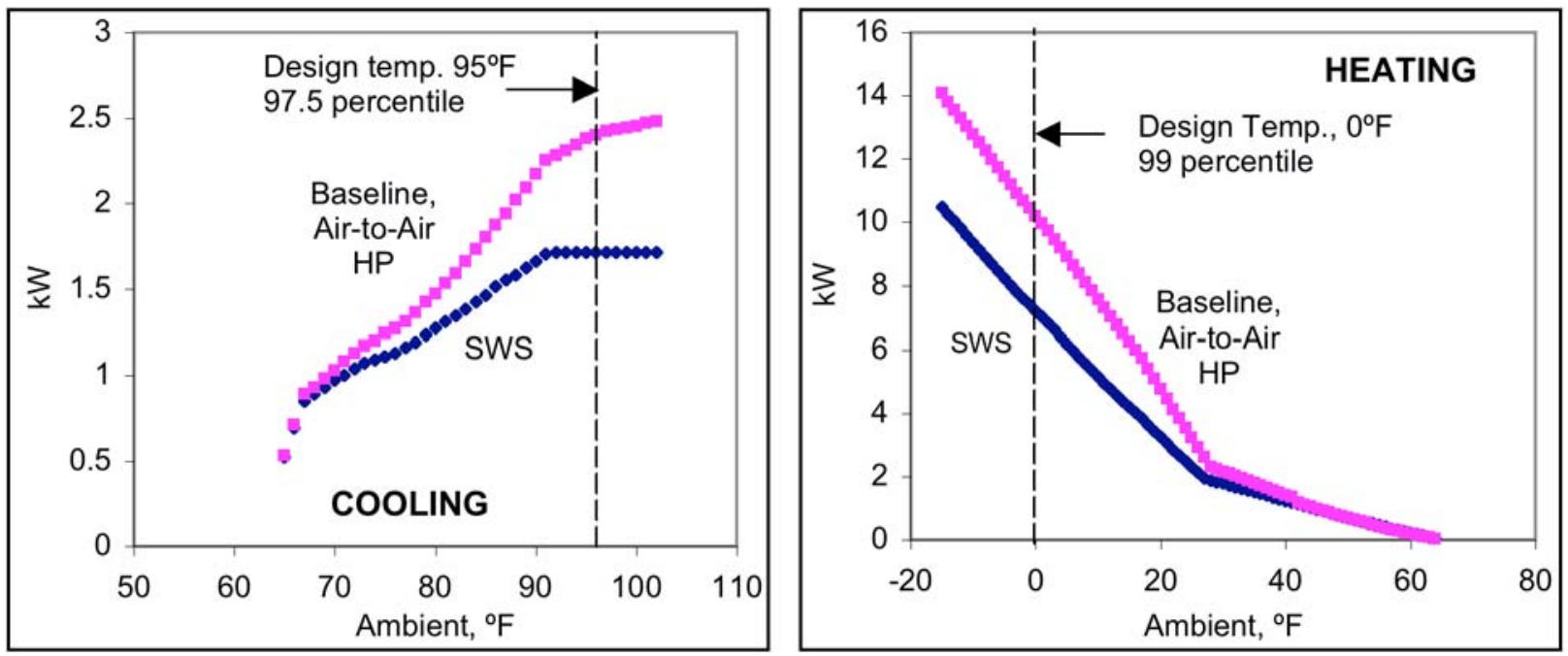
Comparison of aggregate electricity demand of SWS versus conventional air-to-air heat pump technology shows substantial electricity savings during summer and winter months when outdoor temperatures are hot and cold, respectively. Aggregate peak electricity demand may be reduced as much as $45 \%$ and $35 \%$ during the summer and winter months, respectively, using SWS as shown below (Figure 8) (Rice 2004).

Figure 8. Aggregate percent peak savings with SWS: Cooling (daytime) and Heating (nighttime)
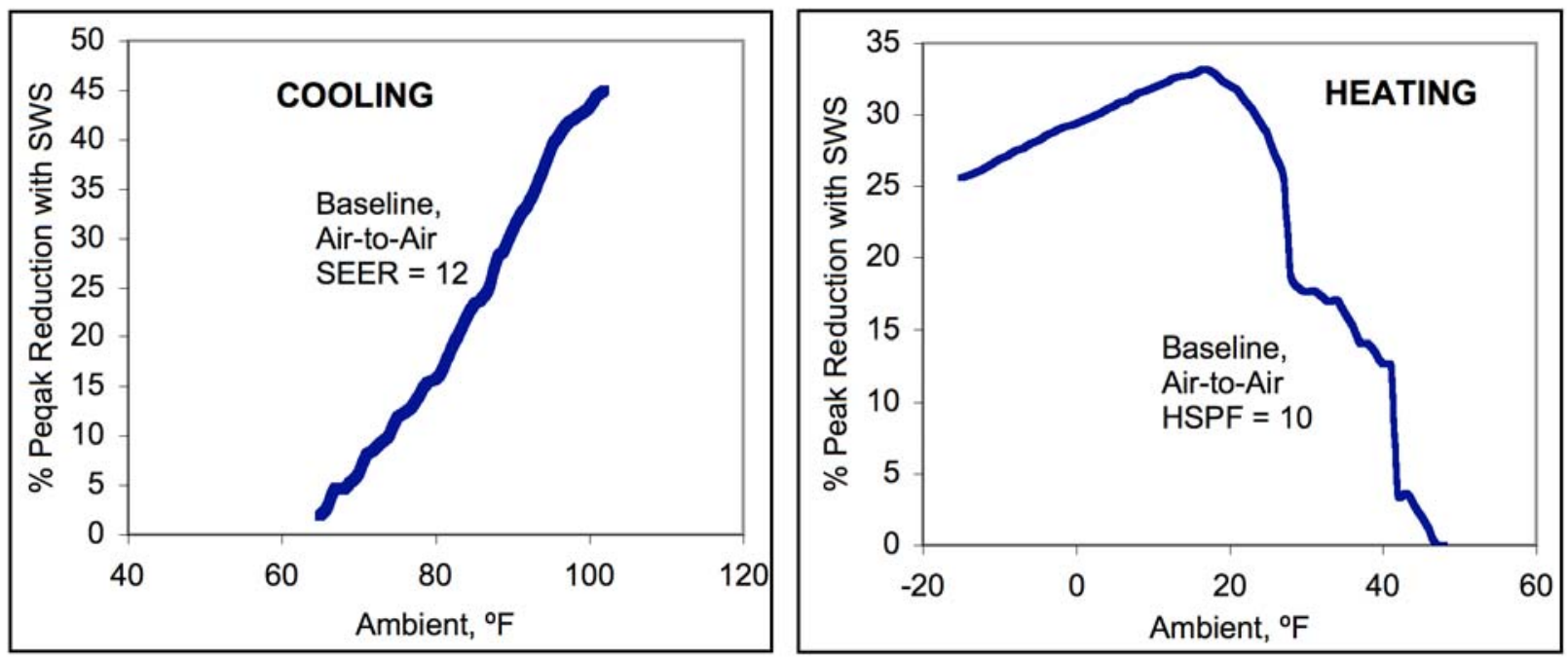

\subsubsection{Potential energy savings}

The ORNL heat pump model analysis between a conventional air-to-air heat pump and an SWS ground-coupled heat pump installed in DOE's Region III shows annual electricity savings of $36 \%$. Other regions with broader air temperature extremes should see greater savings. The AEO2004 reports 11 million air-to-air residential heat pumps and only 88 thousand geothermal residential heat pumps in 2003. Even with a $9.1 \%$ growth rate for geothermal, this still represents only 550 thousand residential geothermal heat pumps by 2025. Development and deployment of SWS heat pumps will improve energy savings two ways. By making these projected geothermal heat pumps more efficient, there will be savings over those that are projected to be used. Secondly, and perhaps more importantly, the lowered cost and increased flexibility of the SWS heat pumps could greatly expand their market penetration into the air-to-air heat pump market. By 2025, the AEO2004 reports the average geothermal heat pump cooling efficiency at 14.82 SEER, while air-to-air heat pumps have a SEER of 13.08. If the SWS can improve efficiency by $35 \%$, this could represent an average SEER of 17.7. Of course, more detailed analysis of market potential (such as with NEMS) could distinguish the amount of market that SWS may capture. Commercial market penetration would need to be explored as well.

As a very rough approximation of potential savings, the residential electrical consumption for space heating in 2025 totals 1.4 Quads in the AEO2004. Assuming conservatively based on 1999 ratios that one third of the heat is provided by heat pumps (versus resistance heating) and there is an equal amount of energy used for cooling from heat pumps, a 35\% savings from SWS heat pumps over air-to-air heat pumps would equal 0.32 Quads. In the commercial sector, 0.5 quad of primary energy for electric space heating converts into 0.11 Quad potential saving, using the 
same factors as for residential. In the AEO2004 reference case, geothermal heat pumps provide only 0.01 Quads of energy. It is unknown how rapidly SWS could penetrate (and possibly expand) the heat pump market. Assuming through a combination of penetration and expansion it could take $50 \%$ of the expected heat pump market, this would be equal to savings of 0.21 Quads.

For a detailed analysis of market energy savings, the heat pump model must be run for each of six regions in the continental USA along with information on residential population density and potential commercial applications as well as heat pump size distribution. For a rough analysis, the seven air-conditioning and heat pump manufacturers in the U.S shipped 6.2 million air-to-air and geothermal heat pump units in 2001(DOE 2003). In addition, heat pumps have an average lifetime of 14 years and 124,000 units were replaced in 2003. If the SWS heat pump's economics proved highly attractive, greater savings could be achieved through increased shares of the natural gas and other heating fuel markets.

\subsection{NEMS approach}

The NEMS commercial module includes ground source heat pumps as an option for heating and cooling. It only allows them in the Assembly, Education, Food Sales, Food Service, Small Office, and Merchandise/Service sectors, not in the Health Care, Lodging, Large Office, Warehouse, or Other sectors. The decision methodology for heat pumps to compete against other sources recognizes the separate heating and cooling they provide. By subtracting the cost of central air conditioners from the heat pump cost before it competes in the heating category, its incremental heating cost is compared to other heating sources.

The NEMS commercial module places cost values in terms of \$/output capacity. Using an SWS cost of $\$ 5,200$ for a three-ton $(36,000 \mathrm{Btu} / \mathrm{hr})$ heat pump, this equals $\$ 144 / 1000 \mathrm{Btu} / \mathrm{hr}$. This makes it more expensive than the typical air-to-air heat pump but less than the high efficiency or other geothermal heat pumps.

Table 10. NEMS example commercial heat pump parameters from the AEO2004 (EIA 2004) and corresponding SWS values

\begin{tabular}{|c|c|c|c|c|}
\hline & $\begin{array}{c}\text { Efficiency } \\
\text { (Btu out/Btu in) }\end{array}$ & $\begin{array}{l}\text { Capital Cost }(2001 \$ / \\
1000 \mathrm{Btu} \text { out } / \mathrm{hr})\end{array}$ & $\begin{array}{l}\text { O\&M Cost (2001\$/ } \\
1000 \text { Btu out/hr) }\end{array}$ & $\begin{array}{r}\text { Lifetime } \\
\text { (years) }\end{array}$ \\
\hline Geo HP 2005 typical & $\begin{array}{l}3.4 \text { (heat) } \\
3.96 \text { (cool) }^{1}\end{array}$ & $\$ 166.67$ & $\$ 1.46$ & 20 \\
\hline Geo HP 2010 high & $\begin{array}{l}4.3 \text { (heat) } \\
6.15 \text { (cool) }^{1}\end{array}$ & $\$ 208.33$ & $\$ 1.46$ & 20 \\
\hline $\begin{array}{c}\text { Air-to-Air HP } 2005 \\
\text { typical }\end{array}$ & $\begin{array}{l}2.2 \text { (heat) } \\
3.52 \text { (cool) }\end{array}$ & $\$ 97.22$ & $\$ 3.33$ & 14 \\
\hline Air-to-Air HP 2010 high & $\begin{array}{l}2.87 \text { (heat) } \\
5.28 \text { (cool) }\end{array}$ & $\$ 155.56$ & $\$ 3.33$ & 14 \\
\hline SWS & $\begin{array}{l}3.22 \text { (heat) } \\
4.0 \text { (cool) }\end{array}$ & $\$ 144.44$ & $\$ 1.46$ & 20 \\
\hline
\end{tabular}

The NEMS residential module also includes ground-source heat pumps, but in a different format than the commercial module. Key factors include the start year, end year, efficiency, capital cost, and retail (replacement) cost for heating and cooling. The inputs allow a change in efficiency or cost by setting different years when equipment can be installed, with improved equipment available in later years. Table 11 shows values for two of the air-source and geo-source heat 
pumps available 2006-2019, along with representative values for the SWS. While the SWS technology is not as efficient as the other geothermal heat pumps, its cost is much less.

Table 11. NEMS example residential heat pump parameters from the $A E O 2004$ and corresponding SWS values

\begin{tabular}{|c|c|c|c|}
\hline & $\begin{array}{c}\text { Efficiency } \\
\text { (Btu out/Btu in) }\end{array}$ & $\begin{array}{c}\text { Capital Cost } \\
(2001 \$)\end{array}$ & $\begin{array}{c}\text { Replacement } \\
\text { Cost }(2001 \$)\end{array}$ \\
\hline Geo HP \#1 & 3.4 (heat) & $\$ 6,760$ (heat) & $\$ 4,000$ \\
& 13.5 (cool) & $\$ 3,640$ (cool) & \\
\hline Geo HP \#2 & 4.3 (heat) & $\$ 7,891$ (heat) & $\$ 4,800$ \\
& 21 (cool) $^{1}$ & $\$ 4,249$ (cool) & \\
\hline Air-to-Air HP \#1 & 2.2 (heat) & $\$ 2,345$ (heat) & $\$ 2,000$ \\
\hline Air-to-Air HP \#2 & 3.52 (cool) & $\$ 1,155$ (cool) & \\
& 2.38 (heat) & $\$ 2,580$ (heat) & $\$ 2,333$ \\
\hline SWS & 3.81 (cool) & $\$ 1,271$ (cool) & \\
& 3.22 (heat) & $\$ 3,200$ (heat) & $\$ 3,200$ \\
\hline
\end{tabular}

${ }^{1}$ NEMS values for cooling efficiencies for Geo-HP are inconsistent with other heat pump values in the same input file, (appear to be SEER values so should divide by 3.412). However, source code refers to different mechanisms for calculating GeoHP energy use in which case SWS values should be multiplied by 3.412 .

\subsection{References}

Aristov, Y. I.; Restuccia, G.; Cacciola, G; and Parmon, V. N., 2002 "A family of new working materials for solid sorption air conditioning systems", Applied Thermal Engineering 22, 191204.

Cacciola, G; Restuccia, G, 1994, "Progress on adsorption heat pumps", Heat Recovery Syst. CHP 14 (4) 409-420.

Chua, H. T; Ng, K. C; Wang, W; Yap; Wang, X. L', 2004, International Journal of Heat and Mass Transfer, 47, 659-669.

Chua, H. T; Ng, K. C; Malek, A; Kashiwagi, T; Akisawa, A; Saha, B. B., 1999, International Journal of Refrigeration 22, 194-204.

Department of Energy 2003, 2003 Buildings Energy Databook, Energy Efficiency and Renewable Energy, August.

Department of Energy 2004, DOE/ORNL Heat Pump Design Model, website <http://www.ornl.gov/ wlj/hpdm/MarkVI.html>

EIA 2003, Annual Energy Outlook 2004: With Projections to 2025, DOE/EIA-0383 (2004) Washington, DC: U.S. Department of Energy, December.

$<$ http://www.eia.doe.gov/oiaf/aeo/index.html

Gordeeva, L. G, Restuccia, G, Cacciola, G, Aristov, Y. I, 1998, "Selective water sorbents for multiple applications: 5. LiBr confined in mesopores of silica gel: sorption properties," React. Kinet. Catal. Lett. 63 (1), 81-88. 
Kavanaugh, S., C. Gilbreath, and J. Kilpatrick, 1995, Cost containment for Ground-coupled Heat Pumps, Final Report submitted to the Alabama Universities-TVA Research Consortium (AUTRC), December.

Levitskij, E. A; Aristov, Y, I; Tolarec, M. M.; Parmon, V. N, 1996, "Chemical Heat Accumulators: A new approach to accumulating low potential heat", Solar Energy Materials and Solar Cells, 44, 219-235.

Meunier, F.,1992, "La sorption solide: une alternative aux CFCs", Proc. Symp.: Solid Sorption Refrig., Paris, pp. 44-52.

Rice, C. K. 2004, Personal communications

Saha, B. B; Koyama, S; Lee; J.B; Kuwahara, K; Alam K. C. A; Hamamoto, Y; Akisawa, A; Kashiwagi, T, 2003, International Journal of Multiphase Flow 29, 1249-1263.

Shelton, S. V. 1992, Residential space conditioning with solid sorption technology, Proc. Symp.: Solid Sorption Refrig., Paris, Keynote Paper. 


\section{Integrated Energy Equipment}

\subsection{Technology}

Integration of systems is a powerful method to improve the functions provided by multiple systems. It can lower costs, improve efficiency, reduce space requirements, and make services that are otherwise unavailable attractive to users. Integration occurs in a large number of fields, from combined inventory control/checkout in businesses, to cell phones with built-in cameras for consumers.

A major concept for improving energy efficiency is recognizing the synergy between energy forms needed by different energy end-uses or types of equipment. Integrating the equipment allows the exhaust of one to be supplied to another, lowering the overall energy losses. In addition, integrated systems allow the common use of components for multiple purposes, which can result in lower first costs for systems.

There are a number of examples of integration of energy systems that have been proposed, are under development, or are in current use. Solar photovoltaics on rooftops combine electricity generation and building shell weatherization. This concept has been modified to include solar collectors for piping light indoors or powering bioreactors that produce hydrogen. Integration of hybrid electric or fuel cell vehicles with distributed microgrids could mean electric generation that travels along with people and their consequent demand. On a much larger scale, hightemperature superconducting transmission lines could be cooled by liquid hydrogen produced at the same generation facility, resulting in the distribution of both electricity and gaseous fuels as part of a "supergrid".

Industry has long used integration of energy equipment through cogeneration, providing both steam and electricity to manufacturing processes on the factory floor. The first generating plants in the country provided steam or hot water as well as electricity. Today, cogeneration provides over $9 \%$ of the electricity used in this country (EIA 2003). As equipment has improved, smaller sizes of equipment have become economic, but other factors besides cost begin to enter the decision process when energy is not a major factor for a business or consumer. Improved integration can lower these barriers and foster the acceptance of high efficiency technologies.

\subsubsection{Brief description of the emerging technology}

This chapter will discuss in more detail some ways that integrated energy equipment could be improved so that more commercial and residential consumers can take advantage of the cost and efficiency benefits that they can provide. Possibilities in the residential and commercial sectors include:

- Combined heat pump space heating, cooling, water heating, and dehumidification

- Cool air from heat-pump water heating used for space cooling

- Exhaust heat from refrigeration and freezing used for space heating and/or hot water

- Exhaust heat from distributed electricity generation used for space heating, water heating, and other thermal energy needs

Several of these concepts are already being implemented, most notably the use of thermal exhaust from distributed generation as combined heat and power (CHP). Further expansion of 
these concepts will occur as equipment manufacturers progress from simply routing the energy between equipment to integrating the different pieces of equipment during design. This optimization should lower the cost and improve the overall utilization of energy.

\subsubsection{End-uses}

Integrated Appliances: Some energy needs, such as water heating and space heating, serve to raise temperatures while others, such as refrigeration and space cooling, lower them. Surplus or exhaust heat or cool air from these appliances can be provided to others, boosting the overall efficiency. As a simple example, exhaust air from a domestic clothes dryer could be filtered and ducted to provide heat and humidification to a home during the winter. The end result is an appliance that performs several functions (drying, humidification and heating) that would otherwise require several individual appliances. In a more complex approach, the condenser heat from a domestic refrigerator could be captured and used to provide domestic hot water. Appliances such as air conditioners, heat pumps, refrigerators and dehumidifiers that use compressors and therefore provide heating and cooling at the same time, provide opportunities as integrated appliances that perform dual functions.

There are a number of ways in which appliances may be integrated to perform heating, cooling, humidity control and water heating efficiently, and some products are in the market as shown in Table 12 below. Combined equipment for space heating and water heating are available for residential applications. These commercially available systems use natural gas as a fuel and accomplish space heating and water heating at the efficiency of the gas burner. Relatively little technology exists in terms of residential integrated appliances where heat pumping could be used to significantly reduce overall energy consumption. There are only three manufacturers of the residential heat pump water heater (which also provides space cooling and dehumidification), and they are trying to expand the current market at present. With commercial buildings, heat recovery chillers are available where space conditioning coincides with the need for hot water. The commercial heat pump water heater occupies a small, niche market for buildings such as commercial laundries and fast-food restaurants where there is a need for space cooling and water heating. Estimates put the market for all heat pump water heaters in the range of 2,000 units per year, and most of this market is for the commercial heat pump water heater.

Integrated Energy Systems: The highest and most consistent energy savings from distributed energy resources occur when the thermal exhaust from the electric generation is used for other purposes at the site such as heating, cooling, dehumidification, or steam. Total efficiencies from this combined cooling, heating and power (CHP) can easily exceed 70\% (DOE 2004). A significant hurdle to market development and penetration is the complexity of a CHP system, with different manufacturers for various components. An equipment packager must integrate the various components for each site, resulting in higher costs. Especially for smaller potential users where energy use may not be a major consideration, this added complexity can be sufficient to prevent its acceptance. The potential market for commercial CHP is shown in Figure 9. In addition, many industrial sectors, such as chemical, metals, equipment manufacturing, paper, and food have great CHP potential. 
Table 12. Examples of potential applications for integrated energy equipment

\begin{tabular}{|c|c|c|c|c|}
\hline Application & $\begin{array}{l}\text { Integrated } \\
\text { appliance }\end{array}$ & Primary function & Secondary function & Commercially available? \\
\hline \multirow[t]{6}{*}{$\begin{array}{l}\text { Residential } \\
\text { buildings }\end{array}$} & $\begin{array}{l}\text { Water-heating } \\
\text { refrigerator }\end{array}$ & $\begin{array}{l}\text { Refrigeration of } \\
\text { fresh and frozen } \\
\text { food }\end{array}$ & Water heating & No \\
\hline & $\begin{array}{l}\text { Heat pump } \\
\text { water heater }\end{array}$ & $\begin{array}{l}\text { Domestic water } \\
\text { heating }\end{array}$ & $\begin{array}{l}\text { Space cooling with some } \\
\text { dehumidification }\end{array}$ & $\begin{array}{l}\text { Yes, two product variations: } \\
\text { one an integrated heat } \\
\text { pump water heater with } \\
\text { tank; the other, an add-on } \\
\text { heat pump water heater but } \\
\text { the dehumidification } \\
\text { function has not been } \\
\text { optimized in either. }\end{array}$ \\
\hline & \begin{tabular}{|l|} 
Refrigerator \\
heat pump \\
water heater
\end{tabular} & $\begin{array}{l}\text { Refrigeration of } \\
\text { fresh and frozen } \\
\text { food }\end{array}$ & $\begin{array}{l}\text { Water heating and space } \\
\text { cooling with some } \\
\text { dehumidification }\end{array}$ & No \\
\hline & $\begin{array}{l}\text { Water heating } \\
\text { dehumidifier }\end{array}$ & Water heating & $\begin{array}{l}\text { Two operating modes: (1) } \\
\text { water heating priority with } \\
\text { space cooling and } \\
\text { dehumidification as } \\
\text { secondary benefit, and (2) } \\
\text { dedicated mode for space } \\
\text { dehumidification and } \\
\text { modest sensible heating } \\
\text { when water heating load is } \\
\text { satisfied }\end{array}$ & No \\
\hline & $\begin{array}{l}\text { Multifunction } \\
\text { heat pump }\end{array}$ & $\begin{array}{l}\text { Space heating } \\
\text { and cooling }\end{array}$ & Domestic water heating & $\begin{array}{l}\text { Systems developed in the } \\
\text { past; none currently on } \\
\text { market }\end{array}$ \\
\hline & $\begin{array}{l}\text { Combination } \\
\text { space and } \\
\text { water heaters } \\
\text { (combos) } \\
\end{array}$ & Space heating & $\begin{array}{l}\text { Water heating done by gas } \\
\text { using a furnace or boiler } \\
\text { and a heat exchanger to } \\
\text { provide domestic hot water }\end{array}$ & $\begin{array}{l}\text { Yes by five U.S. } \\
\text { manufacturers }\end{array}$ \\
\hline \multirow[t]{2}{*}{$\begin{array}{l}\text { Commercial } \\
\text { buildings }\end{array}$} & $\begin{array}{l}\text { Heat pump } \\
\text { water heaters }\end{array}$ & Water heating & Space cooling & $\begin{array}{l}\text { Yes by six U.S. } \\
\text { manufacturers }\end{array}$ \\
\hline & $\begin{array}{l}\text { Heat recovery } \\
\text { chillers }\end{array}$ & Space cooling & Water heating & $\begin{array}{l}\text { Current technology is simply } \\
\text { a double-bundle condenser } \\
\text { applied to a chiller. } \\
\text { Improved chillers would } \\
\text { improve the energy savings } \\
\text { potential. }\end{array}$ \\
\hline
\end{tabular}


Figure 9. Potential CHP commercial market by sector (Resource Dynamics 2002)

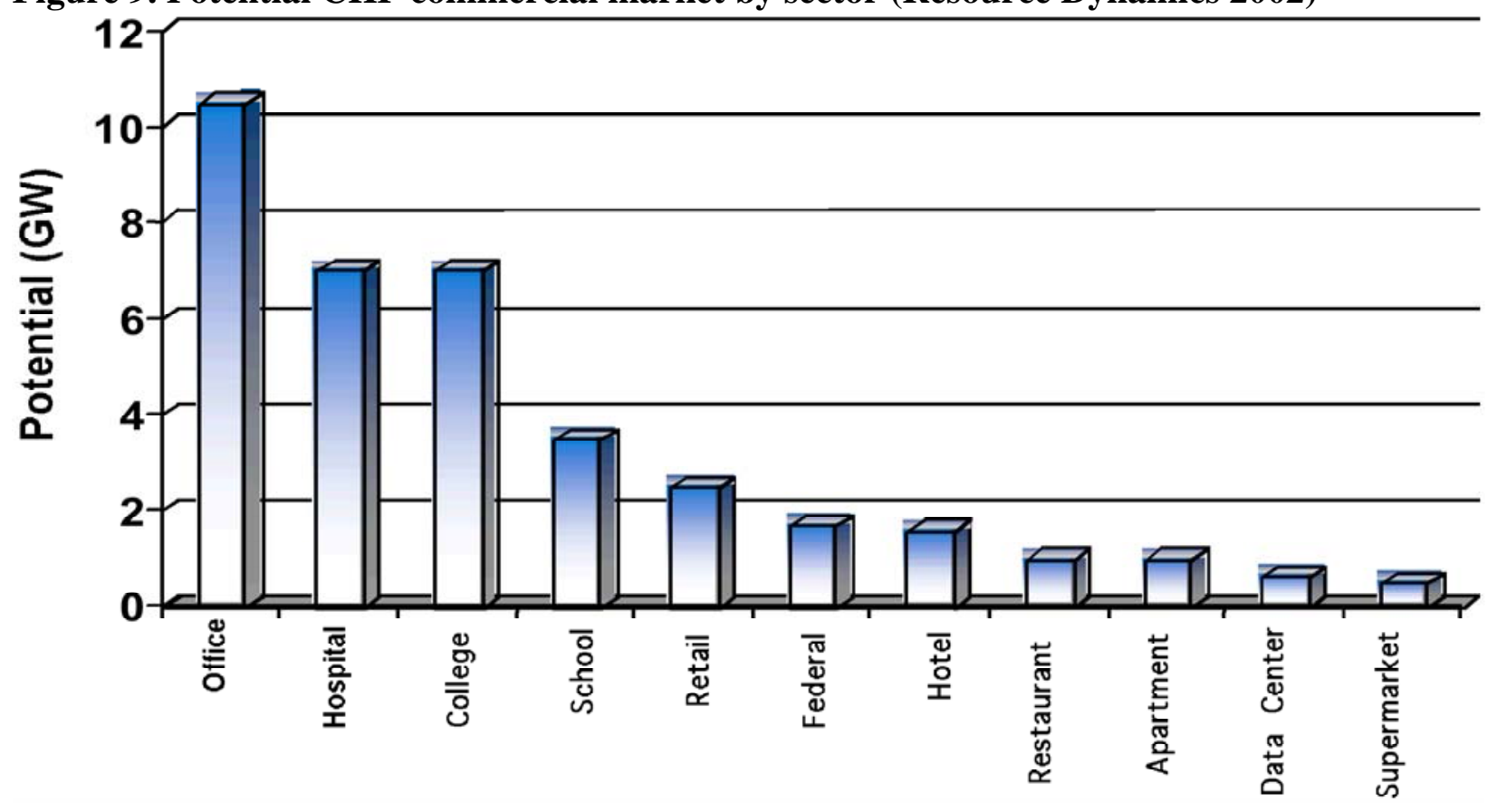

\subsubsection{R\&D needed}

Integrated Appliances: Table 12 above indicates that other opportunities exist for development of integrated appliances, particularly for residential buildings. Additional R\&D is needed in a number of areas:

Heat exchangers - Research on advanced, three-fluid heat exchangers so that heat pumping can be used to exchange energy efficiently and safely between a refrigerant, air or water;

Adaptive controls - Research on adaptive controls that optimize the performance of the integrated appliance for best performance and lowest energy consumption; and

Desiccants - Research on dehumidifying materials (e.g. desiccants) that can be regenerated at low temperatures. These $R \& D$ needs could easily be met in the near term (5-10 year time frame).

Other advances may need a whole-building approach that take longer to advance and implement.

Integrated Energy Systems: Research is ongoing on development of practical integrated energy systems at multiple sizes, increasing the potential market penetration. Currently, United Technologies and Capstone have developed a packaged system consisting of four $60 \mathrm{~kW}$ microturbines plus heat exchangers, chillers, and other equipment to provide space heating, cooling and hot water. NiSource Energy Technologies is developing an integrated system for the hotel industry that combines baseload electricity, heating, absorption-based air conditioning, dehumidification, and emergency isolation from the power grid. The Gas Technology Institute has teamed with Waukesha, Trane, and Ballard Engineering to create a packaged engine generator and absorption chiller for sizes between $280 \mathrm{~kW}$ and $810 \mathrm{~kW}$ for a variety of building types and markets. These are all described in more detail at DOE's Distributed Energy Program website (DOE 2004). 
The individual components within the packaged systems have numerous research challenges as well. For example, microturbines must increase in efficiency by $10 \%$ (from 30\% to 40\%), which is a major materials challenge. Power electronics that interface the electrical production with the grid need improvement to increase the power quality. Fuel flexibility will increase the robustness and value to the user, and emissions reductions are necessary to allow the technology to penetrate markets in areas with poor air quality.

Furthermore, research is being conducted on developing tools to optimize the components of the integrated CHP to balance between electrical and thermal needs. Since different types of commercial (and possibly residential) facilities will have different relative requirements for each type of energy, it is important that the equipment is designed to provide the correct mix at the highest efficiency and lowest cost.

\subsection{Cost}

\subsubsection{Cost of the new technology}

Integrated Appliances: Experience is greatest with residential combined water heating and space cooling. The installed cost of the residential heat pump water heater is $\$ 1200-\$ 1400$ as compared to the $\$ 400$ cost of a conventional electric resistance water heater. Some of the additional cost is related to the additional components needed; however, much of the premium is due to market issues (small current market, lack of infrastructure, no product offering by major manufacturers). High first cost was also a major barrier for the multifunction heat pump developed by Carrier Corporation and later by Nordyne; consequently, only a small market developed for this product. Based on these experiences, it is clear that new integrated appliance designs provide additional customer benefits and better meet customer needs.

Integrated Energy Systems: The cost savings from packaging CHP systems into a single commercial package, as opposed to purchase and installation of individual components, is estimated at 30\% (DeVault 2004). These cost savings are from the economic efficiencies of standardization, lowered transportation costs, and simpler fieldwork.

\subsubsection{Cost-effectiveness}

Integrated Appliances: Since water heating is a significant component of overall building energy consumption, the heat pump water heater is a good example of cost-effectiveness for certain applications. Data show that a conventional electric resistance water heater costs about $\$ 450$ per year to operate based on typical electric rates. The residential heat pump water heater uses $50 \%$ of the energy of a conventional electric water heater. Therefore, the heat pump water heater would save $\$ 225$ per year in operating cost. Based on an incremental cost of $\$ 800$, the payback for switching to the heat pump water heater would be 3.6 years. However, with continued research and technology experience, the incremental cost of the HPWH could decline to less than $\$ 400$, with a consequent payback of less than two years. This estimate is based on the cost of window air conditioners, which use many of the same components as a heat pump water heater and can cost less than $\$ 200$ currently. It is likely that other integrated appliances would have similar economics as well, and similar opportunities for improvement with further research and with manufacturing experience. 
Integrated Energy Systems: Cost effectiveness of the overall technology depends on a broad number of site-specific characteristics including electrical and thermal energy needs, electricity and gas rates, utility cooperation on installation, building owner investment hurdle rates, and value of reliability.

\subsection{Energy}

These types of equipment integration could significantly improve the overall efficiency for residences and commercial facilities. The amount of market penetration of these improvements will depend on the first and long-term costs, performance, flexibility, and reliability of the equipment and the rate of equipment replacement in applicable buildings.

\subsubsection{Energy consumption}

Integrated Appliances: The energy consumption of an integrated appliance depends on the type of appliance and its application. In the case of a water-heating refrigerator, the energy consumption would be the same as for a conventional refrigerator ( $600 \mathrm{kWh} / \mathrm{y})$; however, the refrigerator would also provide hot water with no additional energy consumption. In an airconditioning climate, the water-heating refrigerator delivers additive benefits: condenser heat to space is eliminated and hot water is produced as a free benefit. Room dehumidifiers, as another example, use approximately 1,000 kWh/year (ref. E-source), and much of this energy ends up as space heating. A water-heating dehumidifier (integrated appliance) could save on an annual basis, more than half of this energy at an approximate operating cost savings of \$40/year.

Integrated Energy Systems: Energy consumption by the technology would be roughly equivalent to the equipment in a non-packaged form. The difference is in the equipment cost, and consequent potential for market penetration. For microturbines, NEMS shows electrical and total (including thermal energy) efficiencies as shown in Figure 10.

Figure 10. Microturbine and Gas Engine efficiency assumptions - Electrical and Total (including thermal) from the $A E O 2004$ (EIA 2004)

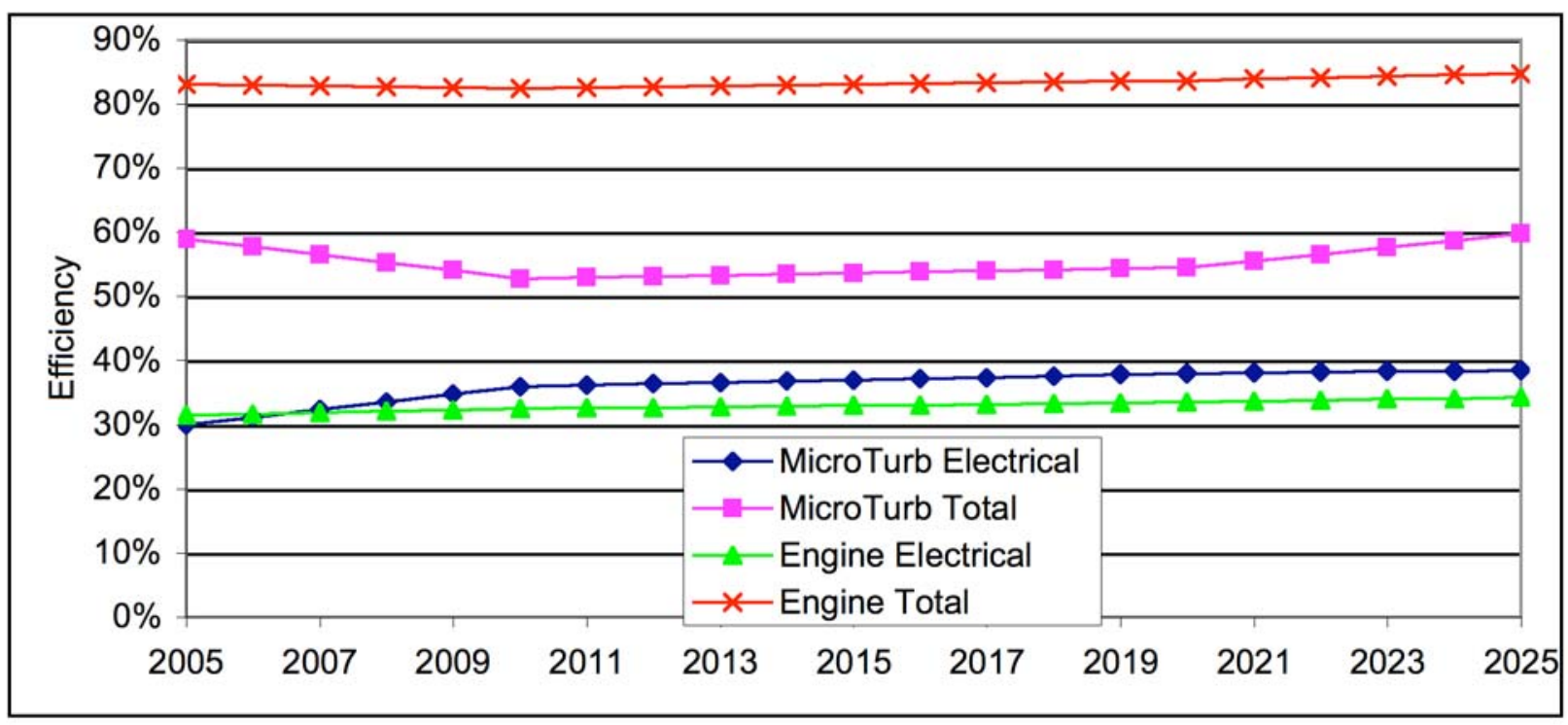




\subsubsection{Potential energy savings}

Integrated Appliances: Integrated appliance types span the gamut from water-heating dehumidifiers to heat pump water heaters, and therefore, there is a wide range of energy savings depending on the technology. For example, the typical heat pump water heater saves on average $2100 \mathrm{kWh} /$ year, and the integrated water-heating dehumidifier $500 \mathrm{kWh} /$ year. The market for electric residential water heaters is about 4 million per year, and the market for dehumidifiers is 1 million per year. A reasonable approach is to assume averages for these technologies over two rates of penetration. At a penetration rate of $10 \%$ per year, the end-use energy savings would be 900 million $\mathrm{kWh} / \mathrm{year}$ or 9.6 trillion Btu of primary energy.

Another way to look at potential savings is the expected electric water-heating load. The AEO2004 shows residential electric hot water energy use at 0.37 Quads (EIA 2003). Integrated heat pump water heaters and space coolers can heat water at over twice the efficiency of a resistance heater, plus the savings from reduced air conditioner load. This gives a minimum potential of 0.2 Quads for this end-use and sector alone. While penetration will likely not be near $100 \%$, other integrated technologies have additional potential savings.

Integrated Energy Systems: The energy savings from packaged systems will come principally from increased penetration of the distributed generation and CHP market. In the AEO2004 reference case, $12.4 \mathrm{GW}$ of commercial distributed generation is deployed by 2025 . Packaged systems should increase that amount if it succeeds in improving the acceptability of CHP into new market niches. Besides the energy savings from the increase in the overall market for CHP, packaged systems can be $10 \%$ to $15 \%$ more efficient than the equivalent energy end-use production from separate equipment. Integration of the design and function allows better utilization of the energy inputs.

In the AEO2004, industrial and commercial CHP provides $157 \mathrm{GWh}$ of electricity in 2002, which translates into 1.7 Quads of primary energy. (Another 2.1 Quads are provided by the electric utility sector for CHP.) The commercial and industrial production is expected to grow to 3.1 Quad by 2025. Most of this production is from large producers for which packaged systems' advantages are not as crucial for acceptance. However, if packaged systems influence the use of just $10 \%$ of this amount, and total energy efficiencies for CHP are double that of central station generation, then packaged systems could result in roughly 0.3 Quads of energy savings. This calculation is very rough; a more complete evaluation would require evaluation of the penetration of packaged systems versus regular CHP systems.

\subsection{NEMS approach}

Integrated Appliances: NEMS models a large variety of residential and commercial building technologies, but currently the only explicit multi-function technology is heat pump for combined space heating and cooling. Heat pump water heaters are modeled as well but the space cooling they provide is not. EIA has plans to add a method that allows flexible multiple-function equipment to be modeled. The initial methodology has been developed by contractors but has not been implemented yet. A bounding analysis of the potential for integrated space/water heat pumps could be done by using the incremental cost of the water heaters but try to limit the acceptance to those who also have heat pumps for space heating. More extensive code changes would be required to explicitly connect the technologies. 
Integrated Energy Systems: NEMS models up to ten distributed generation technologies within the commercial sector. The technology description data includes for each year the information in Table 13. Other parameters such as those concerning program-related penetration, net metering, learning, and operating hours are included in the input file kgentk.txt.

Table 13. Distributed generation technology data used in NEMS

\begin{tabular}{|l|l|l|l|l|l|l|l|l|l|l|l|l|}
\hline Equipment Fuel & First & Last & Avg & Elec & Loss & Degr'd Eq & Tax & Depr & Rec'vlnst. & Equip Maint & Tax Credit
\end{tabular}

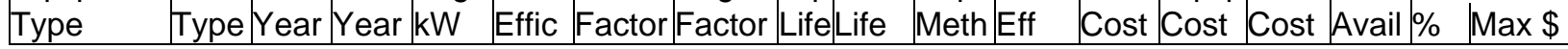

If packaged systems reduce the equipment cost by $30 \%$, then the values in the table for microturbines (if that is the packaged equipment) can be lowered by $30 \%$, giving an equipment profile as shown in Figure 11. Other values would remain the same as for microturbines.

Figure 11. Equipment costs for gas engines and microturbines (from AEO2004 inputs) and packaged microturbines, assuming a $30 \%$ reduction.

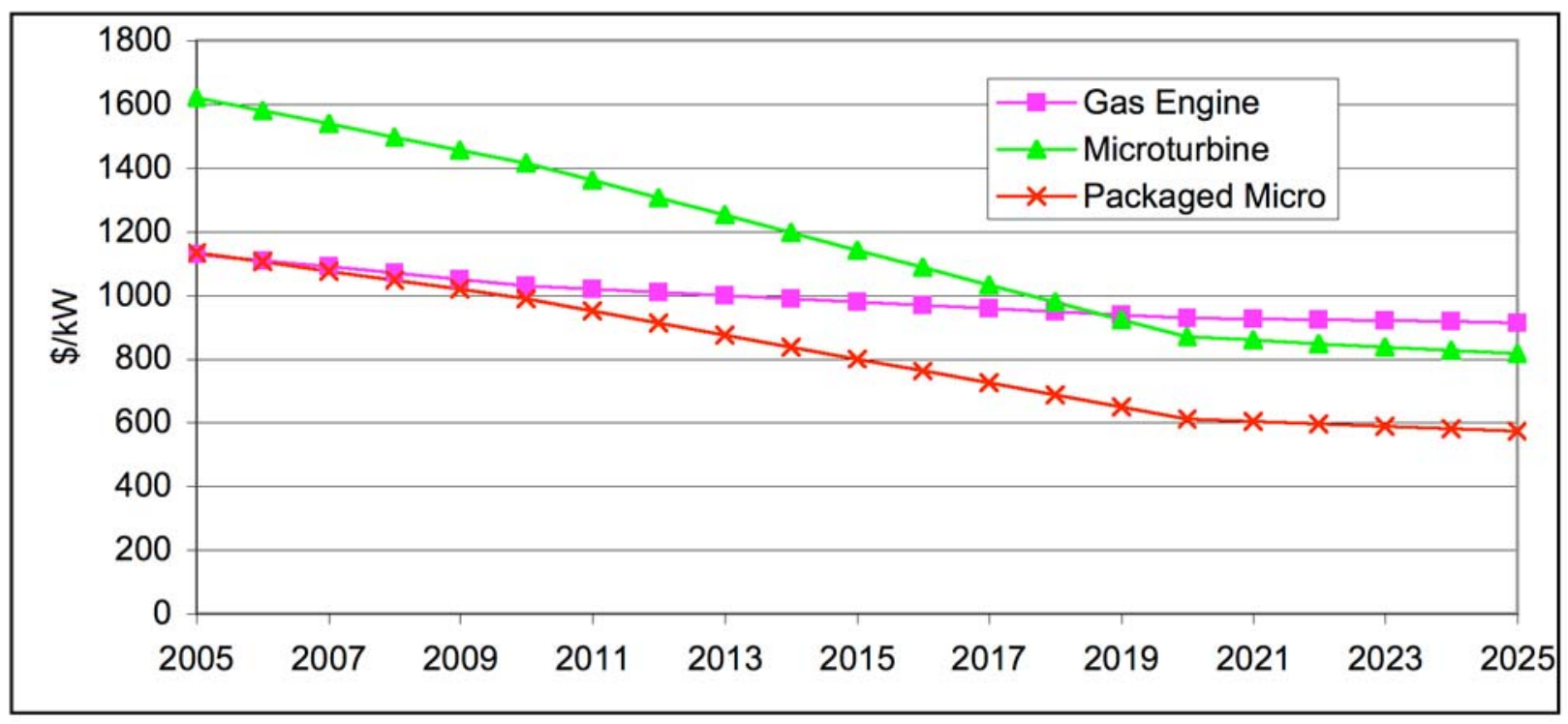

\subsection{References}

DeVault, Robert 2004, Oak Ridge National Laboratory, personal communication.

DOE 2004, "Distributed Energy Program: Distributed Energy Technologies - New Cooling, Heating, and Power (CHP) Packaged Systems Offer Expanded Benefits", Department of Energy website, <http://www.eere.energy.gov/de/technologies/euid_bchp_packgd.shtml>

EIA (Energy Information Administration) 2003, Electric Power Annual 2002, DOE/EIA0348(2002), Department of Energy, December.

< http://www.eia.doe.gov/cneaf/electricity/epa/epat1p1.html>

EIA 2003, Annual Energy Outlook 2004: With Projections to 2025, DOE/EIA-0383 (2004) Washington, DC: U.S. Department of Energy, December.

$<$ http://www.eia.doe.gov/oiaf/aeo/index.html 
EIA 2004, Assumptions for the Annual Energy Outlook 2004 with Projections to 2025, DOE/EIA-0554(2004), U. S. Department of Energy, February.

< http://www.eia.doe.gov/oiaf/aeo/assumption/index.html>

Resource Dynamics, 2002, Integrated Energy Systems (IES) for Buildings: A Market Assessment, ORNL/SUB/409200, Oak Ridge National Laboratory, August. 


\section{Efficient Operations Technology}

\subsection{Technology}

Research has indicated many reasons why energy efficiency varies so much in commercial buildings. The causes of variation in efficiency can be categorized as variations in: efficiency of operation, efficiency of systems, and efficiency of equipment. Of these three, about half of the potential improvement in energy efficiency for commercial buildings would result from operational improvements, with the remainder from equipment and system upgrades.

Many studies have shown the importance of operational improvements, with typical savings of 10-20\% possible in a wide range of buildings (see Haasl and Sharp 1999 for data and additional references). Effective operations provide one of the most cost-effective methods for achieving energy efficiency. Since the Oil Embargo of 1973, the improvement of building operations has been a key means of achieving energy savings. The experience of the Energy Systems Lab at Texas A\&M in the 1980's and 1990's demonstrated that operational efficiency improvement opportunities were still abundant, and experience in the Federal Energy Management Program indicates abundant opportunities remain (MacDonald 2003). The Texas A\&M experience indicated that lowering energy use by $10 \%$ to $40 \%$ merely by improving the operational strategies of buildings was common (Claridge and Haberl 1994).

Despite the demonstrated opportunities, the "technology" for achieving higher-efficiency building operations currently is not based in hardware so much as in software and expert knowledge. Because of this current "soft"-ware dominance, transfer and wide distribution of knowledge is challenging.

Documented research on advanced hardware and software for diagnostics and performance information monitoring has had limited publication (e.g., Piette 2000). Undocumented R\&D is more extensive but remains mostly proprietary (for example, Facility Dynamics Corporation in Maryland has conducted extensive R\&D on both software and hardware configurations, but the technology remains primarily proprietary).

Advances in information technologies such as diagnostic and monitoring software and hardware are still important for achieving improvements in building energy operations. Continued changes toward miniaturization of hardware and toward enhanced measurement and diagnostic capabilities emerge regularly and impact how building operations can be diagnosed and improved.

In recent years, a new class of tools has emerged to make the decision to knowingly seek improved efficiency of building energy operations easier. These tools can be generically called building energy performance rating systems, and the best-known tools of this type in the United States are the Energy Star building certification systems. An extended discussion on the commercial sector, energy use, efficiency issues, and energy certification systems can be found in the forthcoming Encyclopedia of Energy (MacDonald 2004). Figure 12 shows an example readout from the air handling control software for a single floor of a federal courthouse. Use of such software can contribute to the energy savings available through improved operations. 
The challenge is to move all phases of technology development, both hardware and software, toward specifically helping and improving building energy operations, especially in order to be able to conduct diagnostics and remediation on increasingly larger scales with fewer expert personnel required.

Figure 12. Example of air handling unit monitor and controlling software output \begin{tabular}{l|l|l|} 
UNITED STATES FEDERAL COURTHOUSE II & AHU-12A & 12THFLOOR \\
\hline \hline MAINMENU
\end{tabular}

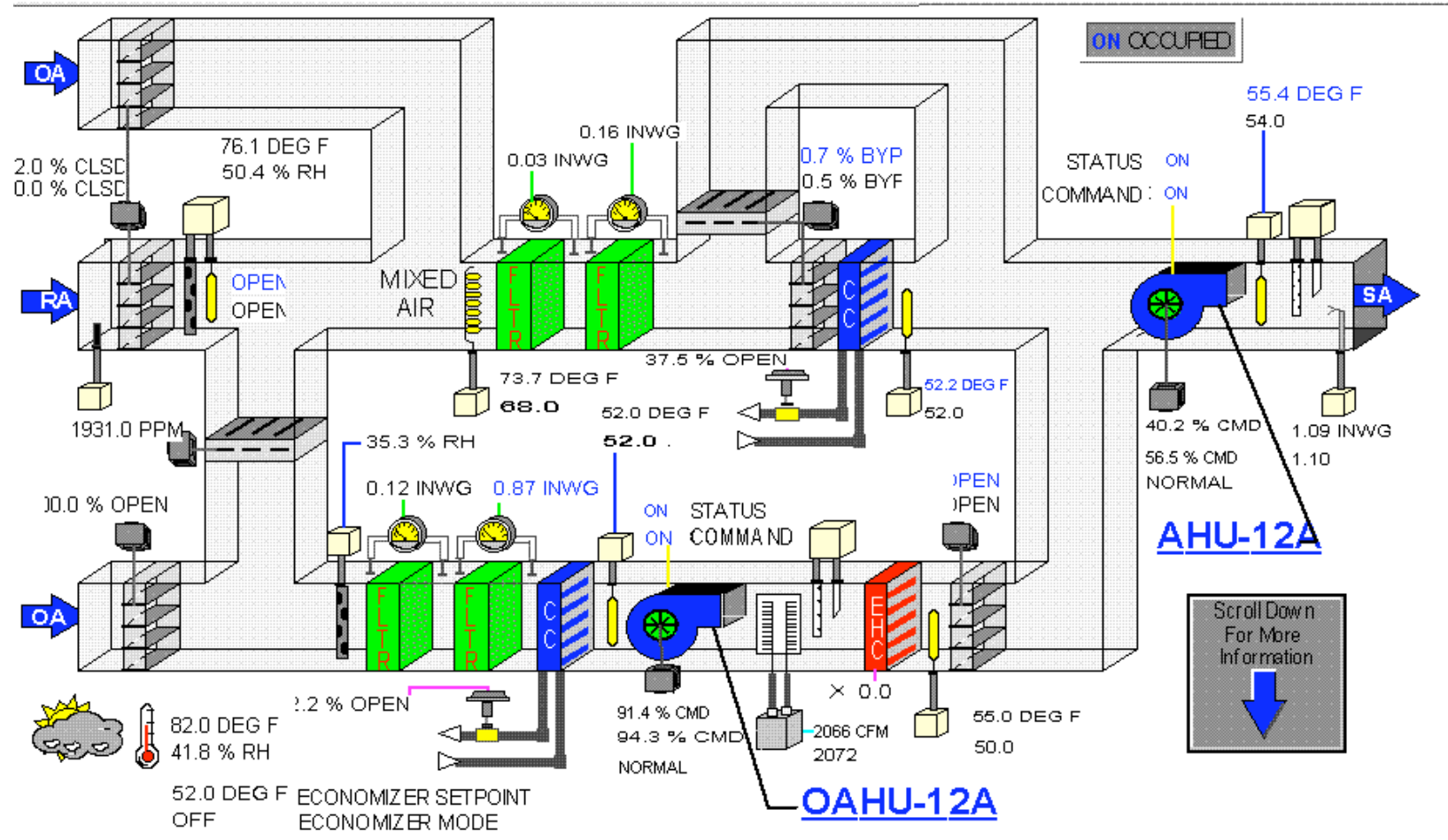

\subsubsection{Brief description of the emerging technology and application}

Energy-efficient operations technology currently involves an event in the life of a building where a systematic investigation and application process for improving and optimizing a building's operation is applied. The focus is usually on energy-using equipment such as mechanical equipment, lighting, and related controls. Improvements in operations strategy and controls are often the major source of benefits. The potential improvements exist because building systems are often very complicated, and many owners and operators are not capable, in many cases, of understanding energy-efficient use of the systems. Increased automation of the improvement process is a potential key area for research and development.

The technology application works best when an initial energy performance rating is determined, an energy assessment is completed (simple may be better here), beneficial hardware and software improvements are identified and prioritized according to objectives for improvement, an energy performance improvement target is set, and improvements are implemented according to priority. 
The energy performance rating of some type is important because then energy performance is measured and the energy improvement potential can be more clearly quantified.

Following the energy performance rating and decision to pursue operational energy-efficiency improvements, expert assessment of the means to achieve improvements in controls and other hardware is still needed.

Enhanced diagnostics and performance information monitoring could potentially allow this step to be performed automatically. A systematic process that optimizes how equipment and systems operate and how the systems function together is needed, and advanced diagnostics and performance assessment algorithms could allow much of this process to be performed by computers.

The key issue of persistence of benefits should also be addressed. In order to ensure that building systems remain optimized over time, a commitment to continuously check the energy performance rating of a building must be made, at a minimum. If performance begins to degrade, benefits also degrade over time. Advanced hardware and software could also allow continuous checking of energy systems performance to help diagnose any causes of reduced performance indicated by the performance ratings.

\subsubsection{End-uses}

The focus of the technology is the major energy end-uses of cooling, heating, HVAC fans, and lighting, although all end uses can be affected.

\subsubsection{R\&D needed}

The technology includes components across the development spectrum. Expert knowledge on the systematic process of energy system evaluation of potential improvements is fairly well developed, although there are still major difficulties in managing the transaction between expert providers and non-expert procurers of such services. Development in sensors and controls is needed to improve their performance and lower their cost.

Energy Performance Rating Systems - The development of energy performance rating systems is, in certain ways, still in its infancy, as so little time has passed since these systems were first successfully developed (in 1999). In addition, the range of building types for which these tools are available is limited, and application in mixed-use buildings is often difficult. Oak Ridge National Laboratory has the only tool available for application in mixed-use buildings, and this tool has not been extensively tested. Significant R\&D on these systems and their application is still important, although a major portion of commercial buildings is currently covered by the Energy Star tools.

Monitoring and diagnostic systems - The major gap in the technology results from the limited development to date of advanced monitoring and diagnostics systems. Advances in reliability and reductions in cost of hardware are needed. Expert knowledge must be codified and transferred to diagnostic and remediation recommendation algorithms.

With the high number of components in a commercial building, it is difficult for operation staff just to keep fully aware of equipment and system conditions. Without automated monitoring and 
fault detection, and the sensors and controls on which they rely, performance can degrade. The number and range of types of sensors installed in commercial buildings today is inadequate to provide sufficient automated (or even visual) monitoring. The primary impediment often cited to more and better sensing is the cost of additional sensors. Installed costs of sensors need to be reduced and decision makers need to become informed regarding the benefits they can derive from better sensing and control.

Automatic control needs to be developed that controls indoor conditions adequately that building staff build confidence in control systems. Control based on more plentiful sensors is required to control at the level desired by occupants and optimize energy use. Optimal control techniques at the system and whole-building level are needed to reach the level of performance where highquality indoor conditions are provided at minimum net energy use. Control must be extended from individual independent loops to system level controls to achieve least-cost, highly efficient, building operation.

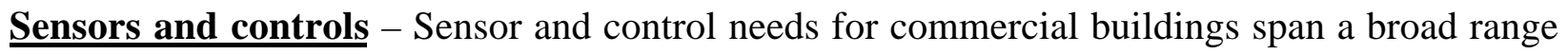
of technical activities. Sensors at a sufficiently low cost are needed for a broad range of measurements that includes lighting quality, volumetric fluid flow rates, rotational position, wear, vibration, and power consumption, as well as the usual measurements of temperature and humidity that are currently performed in commercial buildings. Sensor technology will require built in intelligence to ensure accuracy, self-diagnostics, and be easily integrated into existing systems. These emerging technologies should facilitate broader applications of sensors in buildings including automated diagnostics of HVAC and other energy systems, lighting, fire and safety systems, demand responsiveness and optimal control, indoor air quality, and counter measures against bio/chem attacks (building security).

In addition to possessing lower installed cost than today's sensors, R\&D must lead to sensors with enhanced performance: longer lives, greater reliability, higher accuracy, persistent calibration. These enhancements will lead to higher, persistent, performance of building systems.

Streamlined installation - In addition to improving the quality of sensors themselves, streamlined installation is required. One of the largest cost components for sensors is the cost of installation. Installation, particularly in retrofits, requires running cabling in spaces such as walls and ceilings that are frequently difficult to access, running up expenses for labor. Wireless network technology or communications over existing power wiring can significantly reduce installation costs in new or retrofit applications.

\subsection{Cost}

\subsubsection{Cost characterization}

Cost of applying this technology in its current state varies significantly, depending on several factors. Cost for applying advanced, automated technology is expected to be approximately comparable once lower-cost components are developed and application algorithms are developed. The cost information supplied here is for current technology.

Costs for the energy performance rating vary, depending on whether the energy and characteristics data are already readily available or not, on potential complexities of building use, 
and on potential difficulty with adjusting for major ancillary spaces in a building, e.g., a major computer center in an office building. If data are readily available and no adjustments are needed, an expert can obtain a quick rating in less than an hour, so costs are low, in the range of $\$ 100$.

If data have to be collected for the rating, costs for a rating could be $\$ 1,000-\$ 3,000$, depending on complexity of the data. If major adjustments beyond those typically available are needed for ancillary spaces, costs could increase an additional $\$ 1,000-\$ 10,000$ or more, depending on complexity, e.g., especially if an expert rating assessment is needed or energy use submetering must be installed.

Costs for the expert assessment of improvements needed depend on travel costs, the rigor demanded, the level of reporting required, and the expertise of the assessor. A minimum cost is about $\$ 5,000$ (to at least handle startup). Cost per gross square foot (GSF) of building to be assessed can typically range from $\$ 0.03-\$ 0.08$, depending on these factors, but can be more. For buildings under 100,000 GSF in size, costs will often be higher and possibly driven by a minimum startup cost for the work. As an example, for a 10,000 GSF office building, costs might be $\$ 5,000$ plus $\$ 0.10$ per GSF for a very simple report.

Costs for implementation of actual system improvements might be as low as $\$ 0.05$ per GSF for very large buildings (greater than 500,000 GSF) and could be as high as $\$ 5.00$ per GSF or more for small buildings.

Costs for verifying persistence of benefits should be low, less than $\$ 500 / y$ r per building.

\subsubsection{Cost-effectiveness}

The base technology is to leave operations alone, or to do nothing. Cost effectiveness varies by building energy efficiency rating and building size. As building size increases, cost effectiveness usually increases, due to relatively fixed technology initialization costs. As building efficiency rating decreases, cost effectiveness often increases, although not always, as systems configuration issues and energy costs also have an important influence.

For buildings 100,000 GSF or more, simple payback for implementing operations technology improvements will typically be 0.5-2 years. For buildings 20,000-100,000 GSF, simple paybacks will typically be 2-7 years. Under 20,000 GSF, implementation becomes difficult on a building-by-building basis, although a portfolio of many small buildings might be able to achieve simple paybacks of 5-9 years for the portfolio.

\subsection{Energy}

\subsubsection{Consumption}

This technology uses NO energy per se, but reduces the energy use of existing energy systems in a building. Energy savings of 10-20\% of existing energy use is typical(Haasl 1999, Claridge 1994). 


\subsubsection{Potential energy savings}

For the U.S. commercial sector as a whole, consumption of fossil fuels in buildings directly is a little over 2.6 Quads/yr. Consumption of electricity in these buildings directly is about 1 Million GWh/yr or 9.3 Quads of primary energy. Buildings over 100,000 GSF consume about $38 \%$ of the electricity and about 35\% of the fossil fuel of the sector, for total primary energy use of 4.4 Quads/yr. Using the simplifying assumption that buildings over 100,000 GSF represent the sector's savings potential, together with an average savings of $15 \%$ :

- Electricity savings potential is estimated as $15 \%$ x $38 \%$ x 1 e6 $=60,000 \mathrm{GWh} / \mathrm{yr}$

- Primary energy savings from electricity $=60,000 \times 9287 \mathrm{Btu} / \mathrm{kWh} / 1 \mathrm{e} 9=0.56 \mathrm{Quads} / \mathrm{yr}$

- Fossil fuel savings potential is estimated as $15 \%$ x $35 \%$ x $2.6=0.15$ Quads/yr

- Total technical potential primary savings $=0.56+0.15=0.71$ Quads/yr

These estimates are below what would be estimated using State Energy Data System (SEDS) data for the commercial sector. Achieving these savings requires wide-scale adoption of building energy performance systems, which means further advances in making these simpler and more accessible to ordinary businesses and building operators. Of this total potential, only a fraction of buildings will accept the technology by 2025 . If $10 \%$ of these buildings incorporate these technologies into their operation, then savings would 0.07 Quads/yr.

\subsection{NEMS approach}

Because operations efficiency is an application of technology (software and expertise) that cuts across multiple end-uses, it is more difficult to model in NEMS as an endogenous option. If performance assessments are assumed to occur at major HVAC technology changes, then alternative equipment with higher capital costs (to cover the evaluation) and greater efficiency could be included in the technology options. However, this does not capture the savings from improved operation of other existing energy-using equipment or possible replacement of that equipment at the same time.

Further, NEMS models different commercial sectors, but not the variety of building sizes within each sector. Instead, it applies a total square footage for each sector for each region, expanding this amount as the economy grows, and reducing it as buildings are assumed to wear out (EIA 2004). The increase is modeled as new building area. Equipment in existing space is also replaced based on its life and age, and retrofits can be calculated where the full cost of new technologies is lower than ongoing costs of existing technologies. Limits are placed on the types of technologies that can be considered, and hurdle rates discount future savings compared to capital costs.

Other mechanisms that influence the energy use of buildings are the shell efficiency and weather impacts. In the AEO2004, new buildings are projected to increase their shell efficiency by $7 \%$ by 2025 and existing buildings by 5\% over the 1999 stock average (EIA 2004). Possibly changing these parameters could simulate the gradual influence of operations efficiency. The standard NEMS model assumes a constant climate from 2003 to 2025. Modifications can be made to allow the heating and cooling degree-days to vary over these years. Reductions in these values as compared to 1997 base values should change heating and cooling requirements proportionately. However, use of either of these two mechanisms (shell efficiency or weather) would require 
exogenous estimates of the penetration and effect of operations efficiency improvements on commercial building energy use. Also, they would only affect heating and cooling demands, not other loads such as lighting, which are major contributors to commercial building energy use.

\subsection{References}

Claridge J. and D. Haberl. 1994. "Can You Achieve 150\% of Predicted Retrofit Savings? Is it Time for Recommissioning?," ACEEE 1994 Summer Study on Energy Efficiency in Buildings, pp 5.73-5.87, Washington: ACEEE.

EIA 2004, Assumptions for the Annual Energy Outlook 2004 with Projections to 2025, DOE/EIA-0554(2004), U. S. Department of Energy, February.

< http://www.eia.doe.gov/oiaf/aeo/assumption/index.html>

Haasl, T., and T. Sharp. 1999. A Practical Guide for Commissioning Existing Buildings, ORNL/TM-1999/34, Oak Ridge National Laboratory.

MacDonald, J. M. 2003. "Federal O\&M Audits: Lessons Learned from the FEMP ALERT Program," Proceedings of the 26th WEEC. Atlanta: Association of Energy Engineers. ISBN 088173-420-9.

MacDonald, J. M. 2004. "Commercial Sector and Energy Use," Encyclopedia of Energy, (forthcoming) Elsevier. ISBN: 0-12-176480-X

Piette, M. A. et al. 2000. "Use of an Information Monitoring and Diagnostic System to Improve Building Operations," ACEEE 2000 Summer Study on Energy Efficiency in Buildings, pp 7.101-7.112, Washington: ACEEE. 


\section{Smart Roofs}

\subsection{Technology}

Today there is a great deal of discussion in the roofing industry about cool roofs, green roofs, garden roofs, vegetated roofs and other roof systems that are expected to be more energy efficient and ecologically friendlier than "conventional roofs". Cool roofs have received positive trade press, and some state and federal support for installation where cooling is the dominant building energy load. In mixed climates with both significant heating and cooling loads, the high reflectance that helps in the summer hurts in the winter by turning away solar energy that would otherwise heat the building. ${ }^{1}$ What the roof industry needs is a smart surface that changes reflectance with temperature.

Residential roofing (shingles and clay tile) has a fixed reflectivity with respect to infrared (IR) solar radiation, which is maximally $20 \%$. Over time, this reflectivity degrades through roof wear and subsequently adds to the cooling load during the hotter parts of the year. The technology area presented here is the development of an artificial roof surface that will overlay conventional low slope roofing materials, and which will provide high reflectivity to IR solar radiation in the hotter portions of the year and low reflectivity during the cooler seasons. The technology is based on combining recent developments in optical nanotechnology and polymer science.

An improvement in the roof's ability to modify heat flux based on air temperature therefore has substantial potential for energy savings. Simulations have shown that a roof with a reflectivity of $85 \%$ above $65^{\circ} \mathrm{F}$ and $5 \%$ below $65^{\circ}$ provides estimated energy savings of $5-10 \phi / \mathrm{sq} \mathrm{ft}$-yr over the best available commercial roofing material and from 10-20ф/sq ft-yr over standard shingles in a wide variety of climates.

\subsubsection{Brief description of the emerging technology}

Controlling the optical properties of a surface with nano- and micro-scale physical surface features is a phenomenon that can be found in nature. In the 1960's, it was discovered that the surface of a moth's eye contains small cone-shaped periodic structures that provide a very efficient anti-reflection "coating". ${ }^{2}$ Moths have particularly large eyes and their anti-reflection property has a survival benefit by making it difficult for predators to detect moths in flight from light reflecting from the surface of the eye.

The scientific community has successfully mimicked the cone-like structures found on the moth eye to produce artificial surfaces with anti-reflection properties and is currently investigating the interaction of light waves with a wide variety of surface features and shapes to control optical properties. ${ }^{3}$ The focus of this technology area is to provide large artificial surfaces for roof structures containing nano- and micro-scale features that can effectively control the solar

\footnotetext{
${ }^{1}$ The cost of energy savings based on peak demand charges in northern cities may still make cool roofs a viable option despite the winter energy penalty exceeding the summer savings.

${ }^{2}$ Clapham PB and Hutley MC, "Reduction of lens reflection by moth eye principle," Nature 244(5414): 281-282, 1973.

${ }^{3}$ Hadabos K, et. al., "Reflection properties of nanostructure-arrayed silicon surfaces," Nanotechnology 11(3), 161, Sept. 2000.
} 
reflectivity and thermal emissivity of the surface as a function of the ambient air temperature. For a non-optically transmitting surface, from Kirchoff's law, optical reflectivity and emissivity are inversely related. By customizing the spectral reflectance of the roof, one can control the surface thermal properties. From an energy balance of the roof surface, the key parameters affecting the building's heating and cooling load are the solar reflectance and the IR emissivity.

The key to this technology is then the combination of sub-wavelength structures, to control the reflectivity, with materials that change their optical properties with temperature. The resulting artificial roof surface would provide high reflectivity to IR solar radiation in the hotter portions of the year and low reflectivity during the cooler seasons.

As part of a special technologies program funded by DOE's Defense Programs, ORNL has been investigating artificial surfaces based on sub-wavelength optical structures that provide very high reflectivity for tagging, tracking, and locating in the long wave IR region of the spectrum. ${ }^{4}$ In this region of the spectrum, the current selection of optical materials is sparse and the research at ORNL aims to provide artificial materials that are customizable with respect to a wide variety of optical parameters. The optical properties of the artificial surface depend on the periodicity and refractive index of arrays of physical structures etched or imprinted on the surface. Unlike diffraction gratings, these structures are much smaller in size than the wavelength of the incident light (typically from one third to one half of the wavelength) and are also similar to the types of structures and configurations being investigated in photonic crystal R\&D. ${ }^{5,6}$ Figure 13 shows a periodic array of holes etched in a thin film of silicon on a barium fluoride substrate and also the measured and predicted reflectance in the long wave IR.

\section{Figure 13. Subwavelength optical structure designed for high reflectivity in the IR}

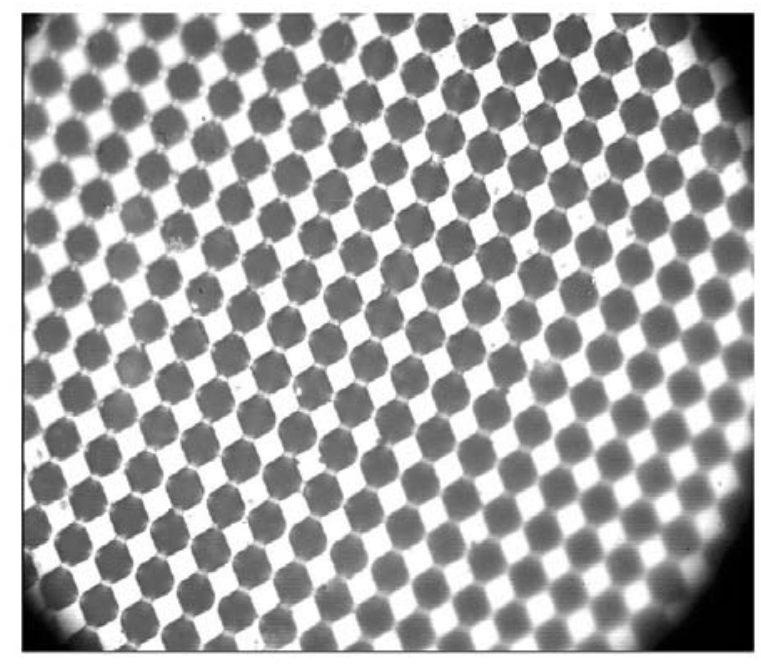

Subwavelength structures in $\mathrm{Si}$ on $\mathrm{BaF}_{2}$

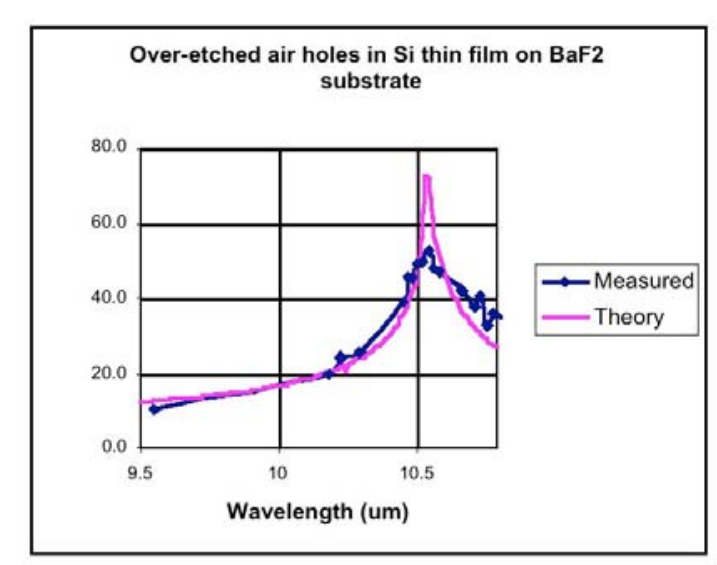

Sample measured reflectance compared with simulated theoretical reflectance

\footnotetext{
${ }^{4}$ Simpson ML, et. al., "Resonant Dust: IR Targets for Tagging and Identification,” JASON Summer Study, La Jolla, CA, June 21, 2001.

5 Joannopoulos JD, et. al., "Photonic crystals: putting a new twist on light," Nature 386, 143-149; 1997.

${ }^{6}$ Joannopoulos JD, Meade RD, and Winn, JN, Photonic Crystals, Princeton University Press, 1995.
} 
What would the smart roof concept look like? The product would consist of four layers. The first layer is the roof substrate whether metal, concrete, thermoplastic membrane or wood. The second layer is a customized polymer layer with a top surface that has a specially designed indentation pattern. The third layer is an opaque material used to fill the nanoscale indentations on the polymer surface. The fourth layer is a clear coating providing both physical and UV protection. The composite can be manufactured as a laminate that overlays the existing roof or that becomes part of the manufacturing process for the respective roof product. As a result, it is not expected to add any weight penalty versus existing roof materials.

\subsubsection{End-uses}

Cool roofs are about saving energy during sunny weather and about mitigating urban heat island effects. These reflective materials are capturing more and more of the market because of the implementation of roof certification protocols initiated by the Environmental Protection Agency (EPA) and the Cool Roof Rating Council (CRRC) and because of state building codes mandating higher and higher reflectance and emittance levels for residential and commercial roofs.

The total sales for new and replacement roof construction is booming and nearly doubled between 1997 and 2000, from \$20 billion to \$36 billion (Good 2001). Of the sales volume in 2000 , low-slope roofing accounted for $64 \%$ ( $\$ 21.7$ billion), while steep-slope "residential" roofing comprised about 35.6\% (\$14 billion) (Good 2001). Almost $70 \%$ of the new low-slope roofs installed in 2001 for the western U.S. were finished in dark absorptive built-up roof (BUR), ethylene-propylene-diene-terpolymer (EPDM) and bitumen-based single-ply membranes (Dodson 2001). However, reflective thermoplastic membranes are capturing more and more of the low-slope roof market, and are the most rapidly growing segment of the United States sheet membrane industry. The 2000 and 2001 market surveys show that the footprint for installed BUR and EPDM dropped 18\%, (Good 2001). While the sales for thermoplastic membranes were up almost 20\% (SPRI, 2003). The time is right for applying the smart roof concept to BUR systems and thermoplastic membranes. The envisioned product can be manufactured as a clear laminate lain on existing low-slope BUR systems. It can also be easily integrated into the manufacture of thermoplastic membranes that are typically rolled over the roof's insulation, overlapped a few inches and welded together using a hot air gun. Hence the smart roof can work for both new and replacement low-slope roof construction.

The metal building industry shipped and installed about 29,000,000 square feet of metal roofs to California in 2002, and about $95 \%$ of the total square footage was finished in low-slope roofing (less than 2-in rise over 12-in of run). Further, about $90 \%$ of the metal roof systems supplied in 2002 for building projects within the state of California used unpainted Galvalume® steel, coated with an aluminum-zinc alloy (Shoemaker 2003). At issue here is the cool roof provisions proposed by the California Energy Code Title 24. The provisions will reduce energy consumption and conserve energy resources; however, the new legislation will also significantly affect the substantial metal roofing market, because the reflectance and emittance of Galvalume ${ }^{\circledR}$ does not meet Title 24 certifications. Further California has a diversity of climates from the alpine climate in the north to the hot desert climate in the southern areas of the state. The circumstances and needs are ideal for implementing the smart roof concept. Metal roofing for commercial low-slope roofs is typically made as structural standing seam metal. Again, a laminate can easily be laid on the metal as an artificial roof surface having combinations of subwavelength optical structures and temperature-sensitive polymers to provide high reflectance to 
IR solar radiation in the hotter portions of the year and low reflectance during the cooler seasons. The laminate with optical structures would also boost the emittance of the roof, because metals typically have low emittance.

A residential homeowner wants a roof to protect the underlying structure for a long period of time at an affordable cost. He is concerned with the issues of appearance and durability; energy efficiency is often ignored. To the homeowner, dark roofs simply look better than their counterpart, a highly reflective "white" roof. What the homeowner does not know, however, is that he can have the best of both worlds. The smart roof can be applied as a clear sheet to the existing steep-slope roof product. The smart roof is adaptable to concrete and clay tile, cedar shake and painted metal residential roofing. However, the composition shingle holds the major market share in residential roofing and application of the laminate poses the greatest technical challenge because of the trade-off between the energy efficiency and the first cost for applying the laminate to an already inexpensive product.

\subsubsection{R\&D needed}

Controlling optical properties using micro and nano-scale structures has been demonstrated on chip-sized surfaces. In addition, available software packages based on finite difference time domain analysis provide accurate simulations of the interaction of light with these structures and are excellent tools for design.

To develop these technologies for "smart roofs", much additional research is needed to provide robust, cost effective, large area surfaces that contain nano-scale structures:

Polymer and material science - Materials with the optical properties needed must be researched. Not only must the materials have high reflectivity, it must be adjustable to react to the changes in temperature, while robust enough to withstand long-term exposure to the elements.

Fabrication technology - Even if a suitable material is found, fabrication processes to make the material acceptable in quality yet affordable must also be determined. Otherwise, the material will not find acceptance in a market dominated by low-cost materials currently.

These are also primary research areas within the current DOE Office of Science nanotechnology thrust. $^{7}$ It is expected that there will be substantial leveraging of on-going research at the National Laboratories, however, it is anticipated that commercialization of the technology is in the 5+ year timeframe.

\footnotetext{
7 Nanotechnology Research Directions: IWGN Workshop Report, National Science and Technology Council, September 1999. http://www.science.doe.gov/bes/IWGN.Research.Directions/welcome.htm
} 


\subsection{Cost}

\subsubsection{Cost of the new technology}

It is too early to provide accurate data on the cost of the new technology. Typical costs for roofing material currently average $\$ 0.80 /$ sq. $\mathrm{ft}$.

\subsubsection{Cost-effectiveness measures}

Simulations described in section 6.3.1 show that a roof with a reflectivity of 0.85 above $65^{\circ} \mathrm{F}$ and 0.05 below $65^{\circ} \mathrm{F}$ has the potential for substantial energy cost reduction in a variety of climates as compared to conventional roofing. Figure 14 shows a comparison of the cost of heating and cooling savings for the best available current practice roof surface (R87E93) and the smart roof ( $\rho$ optimal) compared to a smooth BUR for the three cities cited in section 3.1 having substantially different climates. Cost estimates for the increase in building load were calculated by subtracting the roof energy for a BUR from a thermoplastic membrane that soils with time (R87E93) and comparing those savings with similar savings computed for the smart roof versus the BUR. Service charges for electricity and natural gas were gleaned from the Energy Information Administration (EIA 2001). The field SEER, which describes the performance of the air conditioner, was set at 10 and the efficiency of the gas furnace was assumed moderate at 0.85 .

Figure 14. Cost savings for the smart roof ( $\rho$ Optical) and current practice (R87E93) as compared to the BUR having 0.05-reflectance and 0.90-emittance.

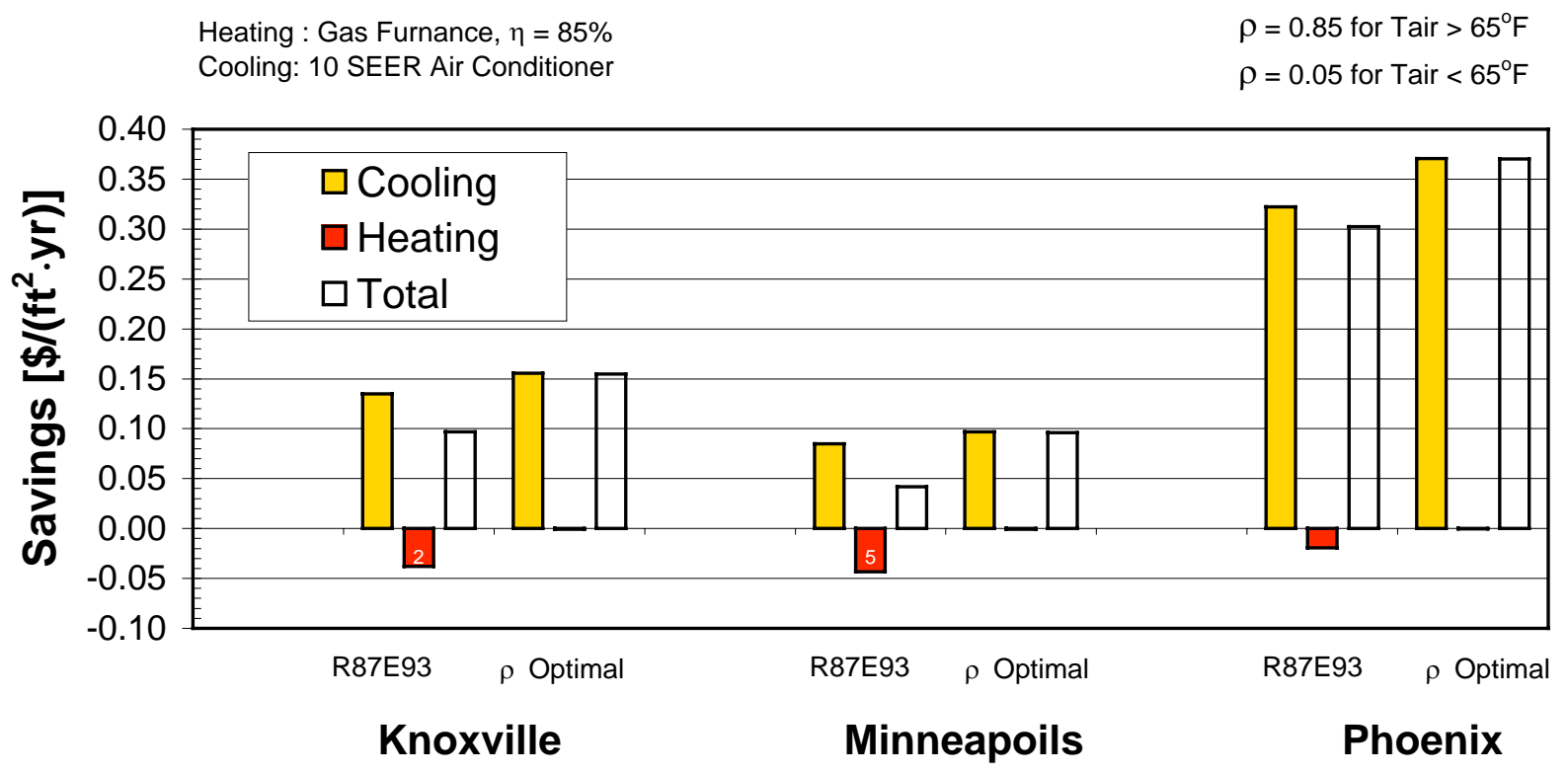

Cost savings are realized in all climates investigated with annual savings increasing about $7 \varnothing$ per square foot of roof per year (see difference in total savings bars for the $\rho$ optimal versus R87E93). Using the manufacturer's data form Shoemaker, the 29 million square footage of low slope metal roofs save about $\$ 2.03$ million dollars annually just in California, which comprises roughly $18 \%$ of the U.S. population. Extrapolating to the US population increases the savings to about $\$ 11$ million annually just for metal roofing. The potential savings and market are there, 
and the opportunity therefore exists to bring forth a new generation of roof products that supports the building owner, the roofing industry and the national economy.

\subsection{Energy}

A building's required comfort cooling and heating energy, termed load, is directly related to several factors: the solar irradiance absorbed by the building; the level of roof, wall, and foundation insulation; the amount of fenestration; and the building's tightness against unwanted air and moisture infiltration. The solar reflectance and long-wave IR emittance and the airside convective currents strongly affect the envelope's exterior roof temperature, which in turn drives the building's cooling and heating load.

Implementing smart roofs would benefit the roof industry by helping them penetrate markets in predominantly heating load climates that previously had no economic justification for reflective roofing. Benefits to the economy are the savings in roof energy because the new products are less susceptible to the wintertime heating energy penalty while still affording energy and peak demand savings in the hot summer months while also improving urban air quality.

\subsubsection{Energy consumption of the new technology}

ORNL's Simplified Transient Analysis of Roofs or STAR computer code predicts the roof surface temperature within about $\pm 5 \%$ of field measurements and predicts the daily roof heat flux within about $\pm 10 \%$ [Petrie et al. (2001a) and Miller et. al (2002)]. STAR generated the annual heating and cooling roof loads for different geographic regions within the United States using typical meteorological year (TMY2) data (NREL 1995). The code calculated the amount of energy cost savings for a smart roof and current practice roof as compared to a smooth, dark BUR with the same amount of insulation but with a solar reflectance of only 0.05 and an infrared emittance of 0.90. The current practice thermoplastic membrane has a reflectance of 0.87 and emittance of 0.93 , identified in Table 14 as R87E93. The STAR simulations accounted for soiling of the thermoplastic membrane (Miller et al. 2002); it lost 50\% of its reflectance due to climatic soiling over three years. For the smart roof, the computations switched the reflectance of the smart roof from 0.05 if air temperature dropped below $65^{\circ} \mathrm{F}$, and up to 0.85 if the air temperature exceeded $65^{\circ} \mathrm{F}$. Table 14 shows the energy savings for the smart roof applied to commercial building having a low-slope roof. Peak demand charges are not included in the analysis.

Table 14. Annual energy savings (Btu/ft ${ }^{2}$ ) for the smart roof ( $\rho$ Optical) and current practice (R87E93) as compared to the BUR having 0.05-reflectance and 0.90-emittance.

\begin{tabular}{|l|c|c|c|c|c|c|}
\hline & \multicolumn{2}{|c|}{ Knoxville } & \multicolumn{2}{c|}{ Minneapolis } & \multicolumn{2}{c|}{ Phoenix } \\
\hline Energy Savings & $\begin{array}{c}\text { R87E93 vs } \\
\text { BUR }\end{array}$ & $\begin{array}{c}\rho \text { Optical vs } \\
\text { BUR }\end{array}$ & $\begin{array}{c}\text { R87E93 vs } \\
\text { BUR }\end{array}$ & $\begin{array}{c}\rho \text { Optical vs } \\
\text { BUR }\end{array}$ & $\begin{array}{c}\text { R87E93 vs } \\
\text { BUR }\end{array}$ & $\begin{array}{c}\rho \text { Optical vs } \\
\text { BUR }\end{array}$ \\
\hline Cooling & 17275 & 19897 & 10534 & 12020 & 32021 & 36854 \\
\hline Heating & -8924 & -175 & -10161 & -156 & -4591 & -86 \\
\hline Annual & 8351 & 19721 & 373 & 11864 & 27430 & 36768 \\
\hline
\end{tabular}

These simulations include the effects of climatic soiling for the thermoplastic membrane R87E93.

Cooling energy savings for the smart roof versus the BUR are about $15 \%$ higher than savings for R87E93 membrane versus the BUR for the climates of Phoenix, Knoxville and Minneapolis (Table 2). More importantly, the smart roof almost fully eliminates the heating penalty observed 
for a reflective roof system versus a BUR (Table 14). As result, annual savings in the hot climate of Phoenix and the moderate climate of Knoxville are 36\% greater than best practice. In heating climate of Minneapolis, the reduction in the heating penalty is very promising and reveals the market potential of the proposed smart roof concept.

\subsubsection{Potential energy savings}

The DOE 2003 Buildings Energy Databook website (DOE 2003) lists the primary energy consumption for space heating and cooling of commercial buildings and residences (Table 15). Low-slope commercial buildings consume about 4.2 Quads of primary energy for space conditioning, and about $15 \%$ is due to the heat transfer through the roof (Huang and Franconi, 1999). Residential energy consumption for heating and cooling is 8.1 Quads, and about 25\% is attributable to the heat leakage through the ceiling and attic of the house (Parker, Sonne and Sherwin 2002).

Table 15. Maximum potential energy savings from smart roofs, Quads

\begin{tabular}{|c|c|c|c|c|c|c|c|c|}
\hline & \multicolumn{2}{|c|}{$\begin{array}{l}\text { Heating Primary } \\
\text { Energy (Quads) }\end{array}$} & \multicolumn{2}{|c|}{$\begin{array}{l}\text { Cooling Primary } \\
\text { Energy (Quads) }\end{array}$} & \multirow{2}{*}{$\begin{array}{l}\text { \% Energy } \\
\text { Loss thru } \\
\text { Roof }\end{array}$} & \multirow{2}{*}{$\begin{array}{l}\text { Savings } \\
\text { from Smart } \\
\text { Roofs }\end{array}$} & \multicolumn{2}{|c|}{$\begin{array}{l}\text { Maximum Potential } \\
\text { from Existing Roofs }\end{array}$} \\
\hline Building Type & Electric & Tota & Electric & Total & & & Electric & Total \\
\hline Com & 0.63 & 2.3 & 1.84 & 1. & $15 \%$ & $25 \%$ & 0.09 & 0.16 \\
\hline & 1. & 6.14 & 1.97 & 1.97 & $25 \%$ & $50 \%$ & 0.44 & 1.01 \\
\hline Total Building & 2.14 & 8.46 & 3.80 & 3.81 & & & 0.53 & 1.17 \\
\hline
\end{tabular}

Assuming that $25 \%$ of commercial energy and $50 \%$ of residential energy could be saved by using smart roofs on buildings, conversion of existing buildings could save 1.17 Quad of primary energy. As the building stock increases, this value would also increase. Of course, conversion of all or even a significant fraction of roofs will take many years. With the long life of roofs, the conservative purchasing behavior of homeowners and contractors, and the amount of research required to develop affordable smart roof materials, decades may pass before a large share of roofs will use this material. The technology is still too new for a market analysis to be done to determine the speed of its acceptance in the market. By 2025, perhaps only $10 \%$ of roofs at most could be expected to use smart roof technologies, giving potential market savings of 0.117 Quads.

\subsection{NEMS approach}

Smart roofs would impact the building shell efficiency of future and existing buildings. In the AEO2004, new buildings are projected to increase their shell efficiency by $7 \%$ by 2025 and existing buildings by 5\% over the 1999 stock average (EIA 2004). Possibly changing these parameters could simulate the gradual introduction of smart roofs. Another method could be through modifications of heating and cooling loads. The standard NEMS model assumes a constant climate from 2003 to 2025. Modifications can be made to allow the heating and cooling degree-days to vary over these years. Reductions in these values as compared to 1997 base values should change heating and cooling requirements proportionately. However, use of either of these two mechanisms (shell efficiency or weather) would require exogenous estimates of the penetration and effect of smart roofs on commercial and residential building energy use. 


\subsection{References}

Dodson, M. 2001. "Looking Great in the West," Western Roofing Magazine, Dodson publications, Inc., Reno, NV, July/August 2001, 32-41.

DOE 2003 “2003 Buildings Energy Databook”, Department of energy website $<$ http://buildingsdatabook.eren.doe.gov/>

EIA. 2001. Form EIA-826, Monthly electric utility sales, and Form EIA-176, Annual report of natural and supplemental gas supply and disposition. Internally search for EIA-826 and EIA-176 on Internet web site http://www.eia.doe.gov/. Washington, DC: U.S. Energy Information Admin.

EIA 2004, Assumptions for the Annual Energy Outlook 2004 with Projections to 2025, DOE/EIA-0554(2004), U. S. Department of Energy, February.

< http://www.eia.doe.gov/oiaf/aeo/assumption/index.html>

Good, C. 2001. "Eyeing the Industry," National Roofing Contractors Association (NRCA) Annual Market Survey, 116-120.

Huang, J., Franconi, E. 1999. "Commercial Heating and Cooling Loads Component Analysis." LBNL-37208.

Joannopoulos, J.D. 1997. "Photonic crystals: putting a new twist on light," Nature 386, 143-149.

Kelso, J., and B. Kinzey. 2003. BTS Core Data Book. Silver Spring, MD: D\&R International, and Richland, Wash.: Pacific Northwest National Laboratory.

Miller, W.A., Cheng, M-D., Pfiffner, S., and Byars, N. (2002). "The Field Performance of HighReflectance Single-Ply Membranes Exposed to Three Years of Weathering in Various U.S. Climates," Final Report to SPRI, Inc., Aug., 2002.

NREL. 1995. TMY2s. Typical meteorological years derived from the 1961-1990 national solar radiation database. Data Compact Disk. Golden, CO: National Renewable Energy laboratory.

Parker, D.S., Sonne, J. K., Sherwin, J. R. 2002. "Comparative Evaluation of the Impact of Roofing Systems on Residential Cooling Energy Demand in Florida," in ACEEE Summer Study on Energy Efficiency in Buildings, proceedings of American Council for an Energy Efficient Economy, Asilomar Conference Center in Pacific Grove, CA., Aug. 2002.

Petrie, T. W., Atchley, J. A., Childs, P. W., and Desjarlais, A. O. 2001a. "Effect of Solar Radiation Control on Energy Costs: A Radiation Control Fact Sheet for Low-Slope Roofs," Proceedings, Performance of the Exterior Envelopes of Whole Buildings VIII: Integration of Building Envelopes. December 2001. Paper 146, CD ISBN 1-883413-96-6. Atlanta, GA: American Society of Heating, Refrigeration and Air-Conditioning Engineers, Inc.

Simpson, M.L. 2001. "Resonant Dust: IR Targets for Tagging and Identification," JASON Summer Study, La Jolla, CA, June 21, 2001 
Shoemaker, W. L. 2003. "Comments Submitted to the California Energy Commission's Energy Efficiency Committee Public Hearing," Thursday, September 4, 2003, Sacramento, CA.

SPRI, Personal communications with SPRI Technical Committee, March 2003. 


\section{Conclusions}

Increasingly, residential and commercial building owners are confronted with the challenge of moving toward a cleaner, more sustainable energy path while maintaining the energy services they desire. Technology will be essential for meeting these challenges. At any given point, business and residential owners are faced with the question of investing in new equipment. At this decision point, new and emerging technologies compete for capital investment alongside more established or mature technologies. Understanding the dynamics of the decision-making process is important to perceive what drives technology change and the overall effect on building energy use. From a policy-making perspective, the better we understand technology developments the more effective we will be in utilizing our future research dollars and in undertaking sound strategy development.

This report focuses on the long-term potential for energy-efficiency improvement in buildings. In 2002, residential and commercial buildings consumed $39 \%$ of the country's primary energy and were responsible for $38 \%$ of the greenhouse gas (GHG) emissions in the U.S. Due to the extremely diverse character of buildings, it is not possible to provide an all-encompassing discussion of technology trends and potentials. Instead, we focus on a number of key technology areas: solid-state lighting, advanced geothermal, integrated energy equipment, efficient operations technologies, and smart roofs. Each section provides a detailed assessment on future contributions to energy efficiency improvement, economics and performance, as well as the potential development path, including potential areas for research, demonstration or other support. Each section also describes ways to model the technology in NEMS (National Energy Modeling System) to aid in further model evaluation of the selected technologies.

Solid-state lighting has the potential to revolutionize the lighting market through the introduction of highly energy efficient, longer-lasting and more versatile light sources. Using a detailed, multi-market analysis of the lighting market, Navigant has estimated that SSL could save between 1.2 and 3.5 Quads of primary energy by 2025. This represents up to $33 \%$ of the expected energy use for lighting (Table 16).

Advanced geothermal heat pumps improve on the efficiency of traditional air-to-air heat pumps while lowering the capital costs and land required for their operation compared to earlier generation geothermal heat pumps. Selective water sorbent systems can use the latent heat of vaporization in groundwater to drastically shrink the footprint of geothermal systems. If the research succeeds, these systems will lower energy requirements by 35\% over air-to-air heat pumps. An estimate of the savings by 2025 could be as much as 0.21 Quads (Table 16).

Integrated energy equipment include both multi-function technologies (cooling, heating, hot water, dehumidification) and packaged combined heat and power technologies that integrate multiple energy services into single pieces of equipment to lower cost and increase efficiency. For such a wide variety of technologies, it is difficult to estimate the potential energy savings but by comparing the market growth and efficiency of heat pump water heaters to conventional water heaters, we find a technical potential residential market savings of 0.18 Quads with an achievable market savings of 0.01 Quads. Commercial and industrial CHP is expected to provide 3.1 Quads by 2025. At twice the end-use efficiency of central station generation, the savings 
would also be 3.1 Quads. Packaged systems may only influence a small part of that overall market, so a rough estimate of savings may be $10 \%$, or 0.31 Quads (Table 16).

Table 16. Summary of primary energy savings from five selected buildings sector technologies. The rationale behind each set is described in their respective sections.

\begin{tabular}{|c|c|c|c|c|c|}
\hline Technology & $\begin{array}{l}2025 \text { Primary } \\
\text { Energy Use } \\
\text { for end-use } \\
\text { (Quad) }\end{array}$ & $\begin{array}{l}2025 \text { Technical } \\
\text { Potential } \\
\text { Primary } \\
\text { Energy } \\
\text { Savings from } \\
\text { Technology } \\
\text { (Quad) }\end{array}$ & \begin{tabular}{|}
2025 \\
Assumed \\
Penetra- \\
tion (\%) \\
\end{tabular} & $\begin{array}{c}2025 \\
\text { Achievable } \\
\text { Primary } \\
\text { Energy } \\
\text { Savings from } \\
\text { Technology } \\
\text { (Quad) }\end{array}$ & Notes \\
\hline $\begin{array}{l}\text { Solid State } \\
\text { Lighting }\end{array}$ & 10.47 & 4 & $30 \%-88 \%$ & $1.23-3.51$ & $\begin{array}{l}\text { Energy savings based on } \\
\text { Navigant detailed analysis using } \\
\text { moderate and accelerated } R \& D \\
\text { strategies for multiple markets }\end{array}$ \\
\hline $\begin{array}{l}\text { Advanced } \\
\text { Geothermal }\end{array}$ & 13.75 & 0.433 & $50 \%$ & 0.214 & $\begin{array}{l}\text { Residential and commercial } \\
\text { electricity use for heating times } \\
2 / 3 \text { to represent heat pump } \\
\text { energy use. SWS savings of } 35 \%\end{array}$ \\
\hline $\begin{array}{l}\text { Integrated } \\
\text { Energy } \\
\text { Equipment }\end{array}$ & $\begin{array}{c}0.37 \\
3.1\end{array}$ & $\begin{array}{c}0.185 \\
3.1\end{array}$ & $\begin{array}{c}5 \% \\
10 \%\end{array}$ & $\begin{array}{l}0.01 \\
0.31\end{array}$ & $\begin{array}{l}\text { First values are estimates for } \\
\text { residential water heating. Second } \\
\text { set for packaged CHP }\end{array}$ \\
\hline $\begin{array}{l}\text { Efficient } \\
\text { Operations }\end{array}$ & 4.4 & 0.71 & $10 \%$ & 0.071 & $\begin{array}{l}\text { HVAC energy use in buildings } \\
>100,000 \text { sq ft. }\end{array}$ \\
\hline Smart Roofs & 12.27 & 1.17 & $10 \%$ & 0.117 & $\begin{array}{l}\text { Main savings from residential } \\
\text { roofs }\end{array}$ \\
\hline $\begin{array}{l}\text { Total } \\
\text { Savings }\end{array}$ & & 9.6 & & $1.95-4.23$ & \\
\hline
\end{tabular}

Many studies have shown the value of improving operations of energy-using technologies within buildings, with typical savings of $10-20 \%$ possible in a wide range of buildings. Advances in information technologies such as diagnostic and monitoring software and hardware are important for achieving improvements in building energy operations. In recent years, a new class of tools, called building energy performance rating systems, has emerged to make the decision to knowingly seek improved efficiency of building energy operations easier. Based on the energy usage in large buildings for heating and cooling of 4.4 Quads, a $15 \%$ savings could mean 0.7 Quads of energy saved. The projected penetration of this sector by these operational improvements has not been analyzed; assuming that $10 \%$ of buildings implement these technologies, there would be a savings by 2025 of over 0.07 Quads (Table 16).

"Smart roofs" represent the development of an artificial roof surface that will overlay conventional low slope roofing materials, and which will provide high reflectivity to IR solar radiation in the hotter portions of the year and low reflectivity during the cooler seasons. The technology is based on combining recent developments in optical nanotechnology and polymer science. Assuming that $25 \%$ of commercial energy and $50 \%$ of residential energy lost through roofs could be saved by using smart roofs on buildings, conversion of existing buildings could save 1.17 Quad of primary energy. By 2025, perhaps only $10 \%$ of roofs at most could be expected to use smart roof technologies, giving potential market savings of 0.117 Quads (Table 16). 
This report demonstrates that the United States is not running out of technologies to improve energy efficiency and economic and environmental performance, and will not run out in the future. The five technology areas alone can potentially result in total primary energy savings of between 2 and 4.2 Quads by 2025 , or $3.8 \%$ to $8.1 \%$ of the total commercial and residential energy use by 2025 (52 Quads). Many other technologies will contribute to additional potential for energy-efficiency improvement, while the technical potential of these five technologies on the long term is even larger. 